\title{
The Impact of Crude Oil Inventory Announcements on Prices: Evidence from Derivatives Markets
}

\author{
Hong Miao \\ Sanjay Ramchander \\ Tianyang Wang \\ Jian Yang*
}

This version: February 3, 2017

Hong Miao is an Associate Professor of Finance, Sanjay Ramchander is a Professor of Finance, and Tianyang Wang is an Assistant Professor of Finance, College of Business, Colorado State University, Fort Collins, Colorado, USA; Jian Yang is a Professor of Finance at the Business School, University of Colorado Denver, Denver, Colorado, and the Honorary Director at Center for Commodity Markets and Behavioral Decision, Dongbei University of Finance and Economics, Dalian, Liaoning, P.R. China.

We thank Bob Webb (the editor) and an anonymous referee for numerous helpful comments on earlier versions. Yang acknowledges the support from the National Natural Science Foundation of China (71571106).

*Corresponding author. Business School, PO Box 173364, University of Colorado Denver, Denver, CO 80217-3364. Email: Jian.Yang@ucdenver.edu. Tel: (303) 315-8423; Fax: (303) $315-8084$

Journal of Futures Markets (Final Revision) 


\begin{abstract}
This study examines the impact of weekly crude oil storage announcements on oil futures and options prices. We document evidence of a strong announcement day effect on both markets, and find prices to move in anticipation of the inventory surprise. Futures returns significantly decrease with positive surprises and increase with negative surprises. There is no evidence of an asymmetric impact on futures prices. Near-the-money options exhibit the greatest price sensitivity, and the magnitude of the price response of both futures and options declines with maturity. The results remain robust even after controlling for various macroeconomic and other storage-related news variables.
\end{abstract}

Keywords: crude oil, futures, options, inventory

JEL Classifications: Q41, G13 


\section{The Impact of Crude Oil Inventory Announcements on Prices:}

\section{Evidence from Derivatives Markets}

\section{Introduction}

Market participants pay close attention to crude oil storage announcements because it conveys information about underlying demand and supply conditions in the economy, and plays an influential role in affecting oil price movements. For instance, a recent Wall Street Journal article reported that U.S. crude stockpiles unexpectedly increased during the week ended August 14, 2015. Specifically, inventory climbed by 2.6 million barrels to 456.2 million barrels, when in fact analysts surveyed by the WSJ had predicted that supplies would decline by 1.1 million

barrels. ${ }^{1}$ Upon release of the actual inventory data on Wednesday, August 19, 2015, futures prices for the nearest contract fell by $4.27 \%$.

This paper investigates the impact of crude oil inventory announcements on oil futures and options prices. Crude oil inventories may change due to a variety of reasons. For example, crude oil stocks may rise due to seasonal refinery maintenance, a slowdown in the summer driving season demand, or greater U.S. crude oil imports. A rising crude oil inventory would be indicative of an increasing supply or/and decreasing demand conditions. Importantly, unexpected changes in storage levels carry information relevant for price discovery in options and futures markets. For example, increases in crude inventories that are greater than anticipated or decreases in inventories that are lower than anticipated are likely to exert downward pressure on

\footnotetext{
${ }^{1}$ Molinski, D. U.S. Crude Stockpiles Unexpectedly Rise, Gasoline Falls, August 19, 2015. Wall Street Journal.
} 
crude prices. On the other hand, crude prices are likely to strengthen if an increase in crude oil inventories is less than anticipated or a decline in inventories is more than anticipated.

An examination of the price response in the futures and options market is relevant for several reasons. First, these markets, due to their inherent liquidity and leverage opportunities, provide an ideal venue to examine how new information is incorporated into prices. Our focus on energy prices is especially relevant since energy markets have been found to carry significant effects on the economy (e.g., Hamilton 1996; Barsky and Kilian 2004; Kilian 2008). These effects are also examined in the context of monetary conditions, OPEC meetings, inventory storage reports, and demand and supply shocks. Barsky and Kilian (2002) study global monetary conditions in the 1970s and find energy prices to be strongly associated with high oil prices and economic stagnation. Horan, Peterson and Mahar (2004) examine implied volatility of options on crude oil futures surrounding OPEC meetings and find that implied volatility embedded in option prices drift upward prior to scheduled information releases and drop afterwards. Lin and Zhu (2004) study the impact of the weekly American Gas Storage Survey Report on natural gas futures price volatility. They find that the weekly gas storage report is associated with price volatility at the time of its release and extends up to 30 minutes following the announcement. Gay, Simkins and Turac (2009) also study the natural gas storage market and show that futures prices are responsive to the surprise component of the EIA announcement. Kilian and Murphy (2012) formulate a structural vector autoregressive (VAR) model to investigate the dynamics of oil market and document the importance of demand and supply shocks on real oil prices.

Second, our study contributes to the larger debate on the role of economic news on oil prices. Research indicates that oil prices have a substantial influence on the economy; however, the reverse implications of the impact of economic news on oil prices have not yielded 
conclusive evidence. Kilian and Vega (2011) find that daily regressions of crude oil and gasoline returns on the surprise components of several U.S. macroeconomic announcements produce insignificant coefficients and low $R^{2}$ values. They interpret the relative lack of responsiveness of returns to economic surprises to suggest that energy prices are predetermined with respect to domestic macroeconomic aggregates; and crude oil and gasoline prices are determined by flow supply and flow demand. Chatrath, Miao and Ramchander (2012) extend Kilian and Vega's study by conditioning the responses of crude oil returns to macroeconomic news on the level of inventories. They show that crude oil remains unresponsive to macroeconomic news even during times of extreme inventory-build-up (or build-down), supporting the conclusions in Kilian and Vega (2011) and Kilian and Murphy (2014).

Elder, Miao and Ramchander (2013) argue that the weak response of energy prices to economic shocks may be an artifact of a particular identifying restriction commonly found in lower frequency VAR models. Using high frequency data, they find that, consistent with economic theory, discontinuities in oil futures prices are significantly related with macroeconomic and industry-specific news events. Wolfe, Kurov and Kucher (2014) estimate the price response coefficients using traditional event study regressions and show that energy prices are more strongly influenced by excess supply and demand shocks than shown in previous studies.

Finally, as an added dimension, our study examines the asymmetric impact of inventory news announcements on crude oil futures prices. Although, there is some prior evidence of the asymmetric price response in commodity markets (see for instance, Elder, Miao and Ramchander (2012) on metal futures), this aspect has yet to be formally investigated for crude oil prices in the context of storage announcements. Our study also examines the influence of EIA announcements 
on the term structure of oil futures and options prices. For instance, Wolfe and Rosenman (2014) study the linkages between the oil and gas markets in the presence of EIA inventory announcements and find a strong bi-directional cross-commodity effect on futures prices for both the next-month nearby futures contract and the following six months' contracts.

The study reports several important findings. In highlighting the results, it is important to note that, to our knowledge, this study is the first to examine the effect of crude oil inventory announcement on option prices. We confirm results from previous literature showing announcement day effects in the futures market; and furthermore, we newly document the presence of similar effects in the options market. Second, in separating inventory announcements into positive and negative surprises, we find futures returns to significantly decrease in response to positive inventory surprises, and increase with negative surprises. This result is consistent with market beliefs on the impact of excess demand and excess supply on commodity prices. Importantly, there is no evidence of asymmetry in the relationship between inventory shocks and futures returns. Third, an examination of the pre-announcement return patterns reveal that both futures and options prices respond in a manner that seem to "correctly" anticipate changes in inventory levels. Such pre-announcement price movements have been documented for OPEC meeting announcements (see Wang, Wu and Yang, 2008). Finally, there seems to be considerable stability in the direction of the response of futures prices and options prices across various maturity categories, although the magnitude of the price response tends to generally decline with maturity. The analysis is subject to a battery of robustness tests. We find that our results are robust to the inclusion of various control variables (macroeconomic news announcements and related inventory variables), as well as the indirect influence of the underlying futures price movements on option prices. 
The remainder of this paper is organized as follows: Section 2 describes the data used in the study. Section 3 presents empirical results and Section 4 concludes the paper.

\section{Data}

Data for U.S. crude oil inventory are obtained from the Energy Information Administration (EIA) Weekly Petroleum Status Report. The EIA report is publicly released each week on Wednesday at 10:30 am (U.S. Eastern Time), with the exception of holidays when the announcement is made on the following day. Consensus forecasts of the inventories in the weekly storage report are obtained from Bloomberg's survey of analysts. The consensus forecast is computed as the median value of the individual analysts' forecast, and is used to calculate unexpected changes of crude oil inventory. We obtain data on the release dates of the weekly storage report, inventory changes and survey forecasts from Bloomberg. The sample period of our study is June 16, 2003 to December 30, 2011, which includes 446 EIA inventory news releases. $^{2,3}$

Daily futures prices for WTI crude are obtained from Tick Data. The WTI futures contracts (Ticker: CL) are traded on both electronic (CME Globex and ClearPort) and open outcry markets. The electronic market is open Sunday to Friday, 6:00 pm - 5:15 pm and the open outcry market is open Monday to Friday, 9:00 am - 2:30 pm (U.S. Eastern Time). At any given point in time, there are several outstanding futures contracts traded with different expirations and transaction prices. The WTI crude oil futures are listed up to nine years ahead using the following listing schedule: consecutive months are listed for the current year and the next five years; in addition, the June and December contract months are listed beyond the sixth year. The

\footnotetext{
${ }^{2}$ June 16, 2003 is the first date Bloomberg reported the analyst survey results on the change in crude oil inventories.

${ }^{3}$ Over this date range, 60 announcements out of 446 total occurred on Thursday.
} 
nearest (front) contracts are typically the most liquid, and therefore most closely examined in prior studies. In this study. we use the first six continuous series: CL1 is the contract with the shortest time to expiration, CL2 is the second shortest contract, etc. We use the simplest possible end-to-end roll algorithm to construct the continuous futures price series with each roll date being the last trading day of a particular contract. By design, the sample construction allows us to examine the influence of liquidity and time to expiration effects on the news-return relationship.

Table 1 presents summary statistics on daily volume, open interest and returns of the first six contracts, CL1 to CL6. Not surprisingly, CL1 has the largest volume and open interest, followed by CL2, and with a sharp drop-off in liquidity for the remaining contracts. The daily average volume of CL1 $(209,436)$ is more than 25 times the daily average volume of CL6 $(8,247)$. Interestingly, the daily average volume of CL1 is approximately the same as its daily average open interest, which implies that the turnover ratio of CL1 is about 1 , or the average holding period is only about one day. This suggests that trading volume may be driven primarily by speculative day- trading. The daily average returns are all positive and range from $0.05 \%$ to $0.06 \%$. The standard deviation of daily returns gets smaller with time to expiration.

\section{[Insert Table 1 Here]}

The light sweet crude oil futures options are traded on the same platform as the light sweet crude oil futures. The underlying asset for the options are the corresponding futures contracts. A put (call) option represents an option to assume a short (long) position in the underlying light sweet crude oil futures traded on the exchange. Trading in the options ends three business days prior to the termination of trading in the underlying futures contract. At any given point in time, there are 36 consecutive months, plus all June and December contracts through nine years. For each expiration, there are one hundred strike prices in increments of $\$ 0.50$ per bbls above and 
below the at-the-money strike price. There are twenty strike prices in increments of $\$ 2.50$ per bbls above and below the highest and lowest fifty increments, and an additional 10 strike prices in increments of $\$ 5.00$ per bbls above and below the highest and lowest 250 increment as described before. Strike price boundaries are adjusted according to futures price movements. The end-of-day option prices for the various strike prices are obtained from the CME Group.

Our sample includes options with up to 730 days ( 2 years) to maturity, since most options with greater than two years to maturity are generally found to be not very liquid. For the purpose of analysis, we classify options into various categories based on moneyness and expiration. Specifically, four time-to-expiration (maturity) categories, ranging from 8 to 180 days, are used as follows: 8-30 days (Expiration 1); 30-60 days (Expiration 2); 60-180 days (Expiration 3); and greater than 180 days (Expiration 4). Next, using Jiang and Tian's (2005) criteria, options are sorted daily on its relative moneyness. For call options, moneyness, $m_{t}=K / F_{t}$, where, $K$ is the strike price and $F_{t}$ is the underlying futures price. Using this definition, we categorize options into five moneyness categories: deep in-the-money (DITM) with $m \leq 0.9$, in-the-money (ITM) with $0.9<m \leq 0.97$, near-the-money (NTM) with $0.97<m \leq 1.03$, out-of-the-money (OTM) with $1.03<m \leq 1.1$, and deep out-of-the-money (DOTM) with $m>1.1$. For put options, the moneyness definition is the inverse of the call definition.

Table 2 presents summary statistics of crude oil futures call options. Consistent with options theory we find that within each moneyness category, the longer the expiration, the higher the price and the lower the implied volatility. Furthermore, within each maturity category, average prices show a distinct negative relationship with moneyness. It is interesting to note that the mean returns for all DITM calls are positive and decrease as maturity gets longer $(1.26 \%, 0.99 \%$, $0.85 \%$, and $0.60 \%$ for maturity categories $1,2,3$ and 4 ). The average returns for ITM options are 
also positive. For NTM options in the first and second maturity categories, the average returns are negative $\quad(-0.86 \%$ and $-0.22 \%)$; on the other hand, the average returns are positive $(0.15 \%$ and $0.22 \%)$ for the third and fourth maturity categories. For OTM and DOTM calls, the average return is negative for all maturity categories. The return characteristics of the sample suggest that profits could have been generated by writing OTM or DOTM call options.

Table 3 presents the summary statistics on put options. In general, the results from put options are found to be qualitatively similar to call options. Comparing call and puts, however, we observe that the average Black-Scholes implied volatility of DITM for puts is higher than the average implied volatility of DITM calls with the same maturity. This is consistent with empirical evidence from options prices at lower frequency, and reflects the premium paid for protection from downside risk. For the remaining moneyness categories, the averages of implied volatility for puts and calls are very similar.

[Insert Table 2 and Table 3 Here]

Unexpected (or surprises) inventory level changes in the EIA report are calculated as: $\left(A_{t}-E_{t}\right)$, where, $A_{t}$ is the actual change of inventory at time $t$, and $E_{t}$ is the expected (i.e., Bloomberg survey median) change of inventory at time $t$. The standardized surprise element of the announcement, $S S I_{t}$ is defined as the surprise component standardized by its unconditional standard deviation. That is $S S I_{t}=\left(A_{t}-E_{t}\right) / \sigma$. Furthermore, we classify inventory changes into positive shocks and negative shocks, based on the relationship between the Bloomberg survey median (proxy of market expectation) and the actual inventory change. If the actual change of inventory is greater than the market expected change, this is labeled as a positive shock. An unexpected increase in storage levels, or positive inventory shock, is expected to dampen prices and negatively impact crude oil returns. On the other hand, we define a negative shock when the 
actual inventory change is less than the market expected change. A negative shock is expected to have a positive impact on returns.

Table 4 reports summary statistics of the Bloomberg survey median, the actual change of inventory, the inventory surprise and standardized surprise. The overall sample (Panel A) is further divided into positive and negative surprises (Panel B) subsamples. There are a total of 446 weekly releases of crude oil inventory changes during the sample period, with 223 announcements classified as positive shocks and the remaining 223 announcements as negative shocks. We find that the Bloomberg survey median is relatively less volatile than the actual numbers - for the overall sample, the standard deviation of the survey (1622.85) is only about one-half of the standard deviation of the actual releases (3474.90). The statistics of the standardized surprise also indicate that consensus survey expectations do not appear to be biased. For the overall sample, the highest standardized surprise is -3.16 and the lowest is 2.97 , and the mean of the standardized surprise is -0.02 . For the negative subsample, the mean is -0.81 with standard deviation of 0.65 ; whereas, the mean and standard deviation for the positive shock subsample are 0.79 and 0.59 .

\section{[Insert Table 4 Here]}

To control for the possible influence of other news releases, we employ a set of 29 macroeconomic announcements (which includes all of the macroeconomic news variables used by Kilian and Vega (2011) and Miao, Ramchander and Zumwalt (2014)) and EIA storage reports of Natural Gas, Gasoline, and Distillate Fuel Oil. The announcement dates, survey median and actual releases are obtained from Bloomberg. Table 5 provides further details of the 32 types of announcements including the full name of the variables, the Bloomberg tickers and the number of observations during the sample period. 
[Insert Table 5 Here]

\section{Preliminary Evidence}

\subsection{Return Patterns around Inventory Announcements - Futures Market Evidence}

In this section, we examine the impact of unexpected changes in inventory on crude oil futures and futures options returns. Inventory announcements are made each week on a Wednesday with the exception of holidays. We measure returns for each trading day during the week to identify the announcement day effect, Day 0, as well as any return patterns before and after the announcement. We compute the average daily continuously compounded returns, $r_{t}=\log P_{t}-\log P_{t-1}$, of the six futures contracts for the two subsamples of positive and negative inventory shocks. These results are reported in Panel A of Table 6. For the subsample of weeks with positive inventory surprises, the average return for contracts of all maturities are positive on Day -2 , negative on Days $[-1,0]$, and then turn positive again on Days $[+1,+2]$. Interestingly, across the different contracts, the magnitude of the pre-announcement day return is higher than the post-announcement day return. For example, the average return for the nearest term contracts are $-0.48 \%$ and $-0.17 \%$ respectively for Day -1 and Day 0 .

In the case of negative inventory surprises, with the exception of Day -2 , the returns for all days, across all maturities, are uniformly positive. The announcement day returns are substantially larger relative to other days. For example, the average return for the nearest dated contracts are $0.56 \%$ on Day $0,0.14 \%$ for Day $-1,0.09 \%$ and $0.18 \%$ for Day 1 and Day 2 , respectively.

Overall, the results confirm expectations that days with positive inventory surprises are associated with negative returns, and negative inventory surprises are associated with positive returns. In the case of positive inventory surprises, the pre-announcement day returns are 
negative and larger in magnitude than announcement day returns. In the case of negative inventory surprises, returns on the day prior to the announcement are positive, although smaller in magnitude than on the announcement day. The behavior of return patterns suggest that the futures market seems to anticipate the direction of inventory movements prior to the announcement. Furthermore, we find considerable stability in the direction of the futures price response along the term structure, although the magnitude of the price response tends to decline with contract maturity.

Panel B of Table 6 reports average daily trading volume for the six contract series, again with the sample split between positive and negative inventory surprises. The largest trading volumes generally occur on Day 1 , followed by Day 0 . The nearest dated contracts are traded most heavily, with volume tapering off significantly. Negative inventory surprises tend to be associated with greater volume than positive inventory surprises.

[Insert Table 6 Here]

Figure 1 shows the behavior of return and volume surrounding the announcement day. Returns are cumulated across a 5-day window spanning $[-2,+2]$ days around the EIA announcement day, i.e., Day 0. Panel A reports trading volume, and it clearly illustrates the peak one day after the announcement, as well as the larger volume associated with negative inventory surprises. Panel B of Figure 1 plots the cumulative average returns, across various maturities, for the $[-2,+2]$ interval surrounding the announcement day. Specifically, returns are cumulated from the beginning of the interval through the end of the week. The spike in returns reported in Table 6 appears in these graphs as a large movement between the pre-announcement and announcement day. Average cumulative returns associated with weeks with negative inventory surprises are always positive, and are uniformly greater than cumulative returns during 
weeks with positive inventory surprises, which, over our sample, are either close to zero or negative. Overall, preliminary evidence confirms the importance of EIA inventory announcements on the crude oil futures market.

\section{[Insert Figure 1 Here]}

\subsection{Return Patterns Surrounding Inventory Announcements - Options Market Evidence}

The response of options to positive and negative inventory surprises are measured across different expirations and moneyness. Daily logarithmic returns surrounding the announcement are reported in Table 7 for call options and Table 8 for put options. Based on market beliefs, we expect positive inventory shocks to correspond with negative (positive) returns for call (put) options on announcement days. We also expect shorter maturity options to display greater responses to prices changes in the underlying asset. These characteristics should be most evident in the NTM (near-the-money) options since they are the most liquid, and therefore less likely to be affected by stale and illiquid prices.

The NTM returns on Day 0 for positive inventory surprises are reported on the left panel in Table 7. Consistent with expectations, announcement day returns are negative and decline in magnitude with maturity. The shortest maturity (Expiration 1) NTM call option has an average announcement day return of $-5.74 \%$, and returns decline monotonically with maturity, to $-2.66 \%$, $-1.20 \%$ and $-0.18 \%$. We also find that the pre-announcement day returns are larger than announcement day returns, which suggests that the options market, similar to the futures market, seems to advance ahead of the news release.

The announcement day returns for ITM and DITM call options provide some interesting contrasts. The longer maturity ITM and DITM options have returns that are slightly positive, but 
close to zero. This is likely an artifact of illiquidity and low sensitivity to the underlying asset, as both decline as option contracts move further away from NTM and longer in maturity. The announcement day return patterns for OTM and DOTM options are quite similar with short maturity contracts carrying the expected sign and are large in magnitude. Further comparisons indicate that the magnitude of returns tend to increase as option strike price increases. That is, the returns of DITM options are smaller in magnitude than DOTM options. DOTM options are typically less sensitive to changes in the price of the underlying asset in dollar times, but their prices are very small in magnitude. This may explain the large percentage returns for DOTM options.

Results for negative inventory surprises are reported on the right-hand columns of Table 7. The announcement day returns for NTM options are positive and decline with option maturity. Similar Day 0 patterns exist for DITM and ITM options, although there are some anomalies found for the illiquid OTM and DOTM options.

[Insert Table 7 Here]

Figure 2 plots the cumulative average returns for calls. From the plots, we observe that for the DITM, ITM, and NTM options, the cumulative average returns for the overall sample have positive slopes. Similar to the patterns documented for futures, the cumulative average returns for weeks with positive inventory surprises trend downwards for Day -1 and Day 0 . On the other hand, for weeks with negative inventory surprises, the cumulative average returns increase across the

$[-2,+2]$ interval surrounding the announcement day.

In comparing the results between options and futures markets, we notice that the cumulative average returns spanning days $[-2,+2]$ for call options are much larger than for the futures 
market. For instance, the cumulative average returns for ITM call options with 8 to 30 days to maturity for weeks with negative shocks is about $14 \%$. By comparison, even for weeks with positive shocks, the largest cumulative average return of futures is less than $1 \%$. The cumulative average returns for OTM and DOTM calls are negative. In particular, OTM and DOTM call options with maturity between 8 and 30 days show very large negative returns both for weeks with positive and negative shocks. The evidence supports the presence of time decay in determining prices.

\section{[Insert Figure 2 Here]}

Table 8 reports the return responses for put option returns for positive and negative inventory shocks. As expected, the results for put options are comparable, but opposite in direction, to that of call options. The average announcement day returns are found to be higher for positive shocks than negative shocks across all moneyness and maturity categories. For DITM, ITM, and NTM puts, the average announcement day returns are positive for positive inventory surprises, and the returns are negative for negative surprises. For OTM and DOTM puts, the average returns are less negative for positive shocks than negative shocks. For instance, on Day 0 , the average return for the nearest term puts are $-11.47 \%$ for positive shocks and $15.43 \%$ for negative shocks.

\section{[Insert Table 8 Here]}

Figure 3 shows the cumulative average return patterns for puts. We observe that the cumulative average returns for puts experience a dramatic shift on announcement day, compared to a perceptible pre-announcement shift for call options. Comparing the results in Figure 3 with Figure 2, for DITM and ITM puts, we notice the cumulative average returns on Day -2 increase for both positive and negative shocks; however, they decrease on Day -1 for negative shocks 
(negative shocks lead to positive price moves for futures and thus negative price movements of puts) and increase for positive shocks. In the case of call options, this apparent divergence in return response starts on Day -1 . The overall evidence suggests that call options seem to carry an advantage in predicting returns relative to put options.

[Insert Figure 3 Here]

\section{Regression Analysis and Results}

We now formally examine the relationship between inventory shocks and announcement day returns examined using a time-series regression analysis, as in Andersen et al. (2003).

\subsection{Regression Results for Futures}

\subsubsection{Simple Regressions}

We first run regressions of the following form for each of the six futures contracts series:

$R_{t}=\alpha+\sum_{i=1}^{3} \beta_{i} R_{t-i}+\gamma_{0} S S I_{t}+\varepsilon_{t}$,

where, $R_{t}$ refers to the daily return of crude oil futures, $S S I_{t}=\left(A_{t}-E_{t}\right) / \sigma$ refers to the standardized surprise of crude oil inventory on day $t$ (zero if there is no inventory news on day $t$ ), and $R_{t-i}$ is the $\mathrm{i}^{\text {th }}$ lagged daily return of crude oil futures. The coefficient $\gamma_{0}$ measures the response of futures returns to an inventory surprise and $\beta_{i}$ measures the autocorrelation effects of the lagged returns. ${ }^{4}$

\footnotetext{
${ }^{4}$ The autocorrelation order for returns in all our different regression models is determined by taking the simple average of the information criteria derived from four tests: Akaike's information criterion (AIC), the corrected
} 
We estimate the models using a two-step weighted least-squares (WLS) procedure. We first estimate the models by ordinary least-squares regression. The time-varying volatility of return innovations obtained from these regressions are then used to perform weighted least-squares estimations of the models. In particular, we regress the natural logarithm of the squared residuals of the ordinary least-squares regression to the predictors (independent variables of the models). The weights derived from reciprocals of the exponential of the fitted values are used to run the WLS regression and obtain parameter estimates.

Table 9 reports the results from this estimation. The estimates for $\gamma_{0}$ for each of the contract series is negative and statistically significant at the $1 \%$ level. For example, the point estimate for $\gamma_{0}$ is -0.482 for the nearest futures contract (CL1), which means that a one standard deviation shock in inventory is associated with a $0.482 \%$ price decrease on the day of the news release. For the sixth contract series (CL6), the parameter estimate (-0.342\%) indicates that a similar one standard deviation shock corresponds to a $0.342 \%$ price decrease. In general, the response coefficients are found to decline as the contract length increases.

[Insert Table 9 Here]

To control for the possible influence of macroeconomic and other inventory-related news releases we run the following regressions:

$R_{t}=\alpha+\sum_{i=1}^{3} \beta_{i} R_{t-i}+\gamma_{0} S S I_{t}+\sum_{k=1}^{32} \theta_{k} S S M_{k t}+\varepsilon_{t}$,

where $S S M_{k t}$ refers to the standardized surprise of the $k^{\text {th }}$ news control variable on day $t$. If there is no release of the $k^{t h}$ news, $S S M_{k t}=0$. Here, $1 \leq k \leq 32$, refers to all of the 29 information criterion (HQC). 
macroeconomic news announcements plus three additional storage releases (specifically, gasoline, natural gas and distillate fuel) from the EIA report (see Table 5).

The results, which are reported in Table 10, indicate that controlling for the influence of macroeconomic and other news result in a modest increase in the magnitudes of the estimated coefficients, $\gamma_{0}$, for all the six contracts. The t-statistics are also higher than the results shown in Table 9. For example, for the nearest contract (CL1), $\gamma_{0}=-0.542$ with t-statistics of -4.31 in Table 10, compared to $\gamma_{0}=-0.482$ with t-statistics of -3.77 in Table 9. Importantly, 13 out of the total 32 news variables are found to have an influence on the daily returns of crude oil futures. The results indicate that the influence of the EIA inventory announcements on crude oil futures returns is in fact stronger after controlling for the impact of other macroeconomic news variables.

[Insert Table 10 Here]

\subsubsection{Asymmetric Regressions}

The asymmetric impact of inventory surprises on oil futures returns are estimated using the following two regressions:

$R_{t}=\alpha+\sum_{i=1}^{3} \beta_{i} R_{t-i}+\gamma^{+} S S I_{t}^{+}+\gamma^{-} S S I_{t}^{-}+\varepsilon_{t}$,

$R_{t}=\alpha+\sum_{i=1}^{3} \beta_{i} R_{t-i}+\gamma^{+} S S I_{t}^{+}+\gamma^{-} S S I_{t}^{-}+\sum_{k=1}^{32} \theta_{k} S S M_{k t}+\varepsilon_{t}$,

where, $S S I_{t}^{+}$and $S S I_{t}^{-}$refer to the positive and negative standardized surprises. That is, we classify the standardized surprises in such a way that if the surprise $S S I_{t}$ is positive then $S S I_{t}^{+}=$ $S S I_{t}$, and $S S I_{t}^{-}=0$; otherwise, $S S I_{t}^{-}=S S I_{t}$, and $S S I_{t}^{+}=0$. They are both zeros when there is no inventory announcement on day $t$. The results are reported in Table 11. 
The estimated parameters show that, when inventory surprises are separated into positive and negative values, both positive and negative shocks share a statistically significant and negative relationship with futures returns. Note when interpreting the results for negative surprises, one must bear in mind that the independent variables are, by construction, negative; therefore, a negative coefficient means that the dependent variable rises in response to the negative surprise in the announcement. In other words, consistent with market beliefs, we find futures returns significantly decreases with positive inventory surprises, and increases with negative surprises.

Results in Panel B indicate that including the macroeconomic announcements do not significantly change the impacts of the positive or negative shocks, except modestly increasing the magnitudes and the t-statistics of the coefficients for both $S S I_{t}^{+}$and $S S I_{t}^{-}$. For example, for the nearest contract, without the macroeconomic factors (Panel A), $\gamma^{+}=-0.552$ with t-statistics of -2.28 and $\gamma^{-}=-0.473$ with t-statistics of -2.27 . In comparison, when controlling for other news variables news (Panel B), $\gamma^{+}=-0.639$ with $\mathrm{t}$-statistics of -2.94 and $\gamma^{-}=-0.443$ with tstatistics of -2.35 . In testing for the equality of coefficients, results show that the differences between the coefficients $\gamma^{+}$and $\gamma^{-}$are not statistically significant for all the regressions in Table 11. Overall, we are unable to document any significant evidence of asymmetry in the relationship between inventory shocks and futures returns.

[Insert Table 11 Here]

\subsubsection{Market Anticipation of Inventory Changes}


To investigate the possibility of market anticipation of inventory changes ${ }^{5}$, while also accounting for the possibility that the survey might not capture all information available immediately before the announcement, we run regressions with the following forms:

$R_{t}=\alpha+\sum_{i=1}^{3} \beta_{i} R_{t-i}+\sum_{j=-2}^{2} \gamma_{j} S S I_{t-j}+\varepsilon_{t}$

$R_{t}=\alpha+\sum_{i=1}^{3} \beta_{i} R_{t-i}+\sum_{j=-2}^{2} \gamma_{j} S S I_{t-j}+\sum_{k=1}^{32} \theta_{k} S S M_{k t}+\varepsilon_{t}$

where, $S S I_{t-j}$ is the lag/lead standardized surprise that allows us to investigate news anticipation effects. Specifically, we consider $j=-2,-1,0,1,2$ in regressions (5) and (6). For instance, on day $j=1$, i.e., one day after the release of the inventory status report, $S S I_{t-1}$ equals the standardized surprise in the previous day. Similarly, on day $j=-1$, i.e., one day before the release of the inventory status report, $S S I_{t+1}$ equals the standardized surprise in the next day. Equation (6) is different from (5) in that it includes the various control variables.

\section{[Insert Table 12 Here]}

The results in Table 12 are largely consistent with our findings from the simple regressions. First, in both Panels $\mathrm{A}$ and $\mathrm{B}$, we observe that the coefficients for $S S I_{t}$ are close to the coefficients in Table 9 with slightly larger magnitudes and higher t-statistics. The signs of the coefficients for $S S I_{t}$ are all negative. For instance, in Table $9, \gamma_{0}$ is -0.482 for the nearest futures contract with t-statistics of -3.77 ; whereas, in Table $12, \gamma_{0}=-0.507$ with t-statistics of -3.97 . Second, the coefficients for $S S I_{t-1}$ and $S S I_{t-2}$ are insignificant for all the 6 contracts with/without news-related control variables. That is, we do not find any persistence of the impact of inventory news announcements on the returns of futures. Third, the coefficients for $S S I_{t+1}$ are significant and negative for all the different contracts. The magnitudes of the coefficients are

\footnotetext{
${ }^{5}$ According to a recent Wall Street Journal article by Rothfeld and Patterson (2013), there is a growing industry using surveillance and data-crunching technology to supply traders with nonpublic information about topics including oil supplies, electric-power production, retail traffic and crop yields.
} 
smaller than the corresponding coefficients of $S S I_{t}$. For instance, $\gamma_{1}=-0.289$ without macroeconomic news and $\gamma_{1}=-0.236$ with macroeconomic announcements. This suggests that the futures market seems to anticipate the surprises correctly one day before the storage announcement. Interestingly, the coefficients for $S S I_{t+2}$ are significant and positive for all contracts. This is consistent with the preliminary evidence reported in Table 6 which shows that for positive announcement shocks, the average returns on Day -2 are positive; whereas, for negative Day 0 shocks, the average returns on Day -2 is negative for all the six continuous futures contracts.

\subsection{Regression Results for Options Returns}

\subsubsection{Simple Regressions and Extensions}

In the case of options, we estimate a similar pooled time-series regression model as Equation (1) by sorting moneyness and expiration. Tables 13 and 14, respectively, report the model estimation results for call and put options. We find that, similar to futures contracts, the options market plays an important role in the price discovery process.

For calls options, at each expiration and maturity, the point estimates for the slope parameter are consistently negative and significant at the $1 \%$ level, with the magnitude of the response larger for call options compared to futures. For example, the point estimate for the shortest maturity NTM call option is -6.06 , which is nearly 12 times as large as the return response of the 
shortest maturity futures contract. The effects of inventory surprises on OTM and NTM call options are relatively larger than for ITM and DITM options, and the effects on near-term call options are more pronounced than corresponding calls with longer maturity.

The results for put options indicate that the inventory parameter is positive and significant at the $1 \%$ level, and the magnitude of the response is lower than for corresponding call options. For instance, a one standard deviation shock results in a price change of about $5.45 \%$ for NTM puts with 8 to 30 days to maturity (Expiration 1 ); whereas, the corresponding impact is $6.06 \%$ for a similar call option. The impacts on expirations and moneyness follow similar patterns as calls, with the effects on near-term put options more pronounced than puts with longer maturity.

\section{[Insert Tables 13 and 14 Here]}

While not reported here, we also run similar regression models with the 32 additional control factors. We find that the impact of inventory shocks remains significant and moderately enhanced by the inclusion of control variables. ${ }^{6}$

The market anticipation regressions are provided in Table 15 and Table 16 for call options and put options, respectively. Note the regression models include the control variables. We find that pre-announcement (i.e., Day -1) prices for both calls and puts move in a manner that seems to anticipate the impact of the impending inventory surprise. For instance, in examining the short-dated NTM options (i.e., Expiration 1), we find that the $S S I_{t+1}$ coefficient is -2.08 for call options and +1.409 for put options - they are both statistically significant at the $1 \%$ level. However, in contrast to futures contracts, there is some evidence of return persistence to the announcement in the options market, as seen by the $S S I_{t-1}$ coefficients. We notice returns to continue in the same direction as the sign of the announcement day returns, suggesting that

\footnotetext{
${ }^{6}$ These results are available from the authors upon request.
} 
option prices fail to fully impound information about crude oil storage levels on the announcement day.

\section{[Insert Tables 15 and 16 Here]}

\subsubsection{Regression Results that Control for Changes in Futures Prices}

The results provide strong support for the information content of the EIA inventory storage reports in facilitating price discovery. In examining options, it is important to note that the underlying asset are corresponding futures contracts. Therefore, it is possible that the observed relationship between inventory shocks and option prices is indirectly driven by the underlying changes in the futures price. In an attempt to isolate these influences, we run the following regression:

$R_{t}=\alpha+\sum_{i=1}^{3} \beta_{i} R_{t-i}+\gamma_{0} S S I_{t}+\theta R_{t}^{F}+\varepsilon_{t}$

where, $R_{t}$ is the daily return of the options, $R_{t}^{F}$ refers to the return of the corresponding underlying futures contract. We estimate this model by sorting moneyness and expiration. The results for call and put options are reported in Tables 17 and 18.

A review of the results in Table 17 indicates that the coefficient estimates for all calls except the deep in-the-money options, with 8 to 30 days to maturity group, are negative and statistically significant at the $1 \%$ level. However, the magnitudes of the coefficients are roughly $13 \%$ of the results in Table 13. For instance, the estimate for shortest maturity NTM call option is -0.792 ; whereas, the corresponding estimate in Table 13 is -6.06 . In other words, when we control for the influence of the underlying asset returns, the impact of inventory shocks on call option returns are found to be weaker, but still statistically significant and comparable in magnitude to the impact on futures returns. The evidence, therefore, suggests that the observed response of call options may be partly attributed to the underlying influence of movements in the futures prices. 
The results from put options in Table 18 provide a great deal of variation. We find that 8 out of the 20 coefficients of $S S I_{t}$ are insignificant at the $10 \%$ level, and furthermore, the signs of the coefficients are not consistent. Therefore, based on these results, we conclude that movements in the underlying futures prices partly contributes to the observed price response of options, especially put options.

Interestingly, in both Tables 17 and 18, we observe very high Adj- $\mathrm{R}^{2}$ values. For instance, the Adj- $\mathrm{R}^{2}$ for NTM with 8 to 30 days to maturity call options is $1.8 \%$ in Table 13 ; whereas, the value is $83.8 \%$ in Table 17 . This indicates that a substantial amount of variability in options return can be explained by the returns of the underlying futures contract.

In comparing our results on the term structure with the previous literature, we find that our regression results from futures options are consistent with Wolfe and Rosenman (2014). The impact of inventory shocks on prices increases as the length of the futures contract decreases, as seen by the coefficients of CL1 through CL6. For all options with same moneyness, longer maturities are associated with smaller inventory surprise coefficients.

[Insert Tables 17 and 18 Here]

\section{Conclusions}

Markets pay close attention to information on crude oil storage levels. Changes in inventory convey information about underlying demand and supply conditions in the economy, and therefore by extension carry implications for crude oil prices. More generally, in examining the role of public news in the determination of crude oil prices, there is considerable debate on whether energy prices are predetermined with respect to macroeconomic aggregates, or the variation of crude oil returns are associated with identifiable macroeconomic and industryspecific news events. 
This paper investigates the impact of the EIA inventory reports on crude oil futures and options markets. Crude oil futures and options markets facilitate price discovery by providing a forum for the assimilation of information held by different market participants regarding both current and future supply and demand conditions. Our research provides insights into the important link between public news announcements and price discovery in crude oil futures and options markets. Specifically, we document crude oil futures and options prices to respond significantly to inventory shocks. In support of market beliefs, we find that physical-market fundamentals in the form of inventory shocks as well as macroeconomic news contain new information in explaining the magnitude and duration of oil price discovery in the derivatives market.

The study reports several additional findings. First, both futures and options prices move in a manner that seem to anticipate changes in oil storage levels, with some evidence of return persistence in the options market. Second, in separating inventory surprises into positive and negative values, we find no evidence of asymmetry in the relationship between inventory shocks and futures returns. Third, an examination of the influence of term structure and option characteristics indicate considerable stability in the direction of response of futures and options prices across various maturity categories, although the magnitude of the price response tends to decline with maturity. Overall, regression results are found to be robust to the inclusion of various macroeconomic and other storage-related control variables, as well as the underlying influence of futures prices in mediating the relationship between inventory shocks and options prices.

The documented price reaction is consistent with prior studies that examine implied volatility surrounding scheduled information releases such as OPEC meetings. However, unlike 
previous studies, the experimental setting created by EIA announcements provides a unique opportunity to relate a market's reaction to scheduled information releases that are directly linked with inventory of the underlying spot asset. The influential role of storage information highlights the relative importance of supply and demand conditions in oil price determination. Additionally, the presence of price response surrounding the announcement day provides new information for regulators and traders in the derivatives market.

Although our focus in this study is on the performance of crude oil futures and options prices, one logical extension would be to examine the impact of these announcements in conjunction with monetary policy shocks and/or output constraints from OPEC meetings. Another interesting topic is to investigate the spillover effects of the energy market to equity markets in the presence of well-defined inventory shocks. We leave these issues for future examination. 


\section{References}

Andersen, T.G., Bollerslev, T., Diebold, F. X., \& Vega, C. (2003). Micro effects of macro announcements: Real-time price discovery in foreign exchange. American Economic Review, 93, 38-62.

Barsky, R.B., \& Kilian, L. (2002). Do we really know that oil caused the great stagflation? A monetary alternative. NBER Macroeconomics Annual. Cambridge, MA: MIT Press. $137-183$.

Barsky, R.B., \& Kilian, L. (2004). Oil and the macroeconomy since the 1970s, Journal of Economic Perspectives, 4, 115-134.

Chatrath, A., Miao, H. \& Ramchander, S. (2012). Does the price of crude oil respond to macroeconomic news? Journal of Futures Markets, 32, 536-559.

Elder, J., Miao, H., \& Ramchander, S. (2012). Impact of macroeconomic news on metal futures. Journal of Banking \& Finance 36, 51-65.

Elder, J., Miao, H., \& Ramchander, S. (2013). Jumps in oil prices: The role of economic news. The Energy Journal, 34, 217-237.

Hamilton, J.D. (1996). This is what happened to the oil price-macroeconomy relationship. Journal of Monetary Economics, 38, 215-220.

Horan, S. M., Peterson, J. H., \& Mahar, J. (2004). Implied volatility of oil futures options surrounding OPEC meetings. The Energy Journal, 25, 103-125.

Gay, G.D., Simkins, B.J., \& Turac, M. (2009). Analyst forecasts and price discovery in futures markets: The case of natural gas storage. Journal of Futures Markets, 29, 451-477.

Jiang, G.J., \& Tian, Y. (2005). Model free implied volatility and its information contents. Review of Financial Studies, 18, 1305-1342.

Kilian, L. (2008). Exogenous Oil Supply Shocks: How big are they and how much do they matter for the U.S. economy? Review of Economics and Statistics, 90, 216-240.

Kilian, L., \& Murphy, D.P. (2012). Why agnostic sign restrictions are not enough: understanding the dynamics of oil market VAR models. Journal of the European Economic Association, $10,1166-1188$.

Kilian, L., \& Murphy, D.P. (2014). The role of inventories and speculative trading in the global market for crude oil. Journal of Applied Econometrics, 29, 454-478.

Killian, L., \& Vega, C. (2011) Do energy prices respond to U.S. macroeconomic news? a test of the hypothesis of predetermined energy prices. Review of Economics and Statistics, 93, $660-671$.

Lin, S.C., \& Zhu, Z. (2004). Natural gas prices and the gas storage report: Public news and volatility in energy futures markets. Journal of Futures Markets, 24, 283-313. 
Miao, H., Ramchander, S., \& Zumwalt, J.K. (2014). S\&P500 Index-Futures Price Jumps and Macroeconomics Announcements. Journal of Futures Markets, 34, 980-1001.

Rothfeld M., \& Patterson S. (2013). Traders Seek an Edge with High-Tech Snooping. Wall Street

Journal.http://www.wsj.com/articles/SB100014240527023034978045792401821872252

$\underline{64}$.

Wang, T., Wu, J., \& Yang, J. (2008). Realized volatility and correlation in energy futures markets. Journal of Futures Markets, 28, 993-1011.

Wolfe, M.W., Kurov, A., \& Kucher, O. (2014). Noisy inventory announcements and energy prices. Journal of Futures Markets, 34, 911-933.

Wolfe, M. H. \& Rosenman, R. (2014). Bidirectional causality in oil and gas markets. Energy Economics, 42, 325-331. 


\section{Table 1: Summary Statistics of Crude Oil Futures}

The table reports the average of volume, open interest and the mean, and standard deviation of the daily returns of the first six continuous crude oil futures contracts (CL1-CL6). CL1 is the closest to expiration contract; CL2 is the series of the second closest to expiration contract, etc.

\begin{tabular}{llcrrrrr}
\hline & \multirow{2}{*}{ Statistics } & \multicolumn{7}{c}{ Contract } \\
\cline { 3 - 7 } & & \multicolumn{1}{c}{ CL1 } & \multicolumn{1}{c}{ CL2 } & \multicolumn{1}{c}{ CL3 } & \multicolumn{1}{c}{ CL4 } & \multicolumn{1}{c}{ CL5 } & \multicolumn{1}{c}{ CL6 } \\
\hline Observations & & 2146 & 2141 & 2142 & 2143 & 2142 & 2139 \\
Open Interest & Mean & 211130 & 186680 & 89155 & 59827 & 46565 & 40835 \\
Volume & Mean & 209436 & 109145 & 38695 & 18956 & 10879 & 8247 \\
Return & Mean & $0.05 \%$ & $0.05 \%$ & $0.05 \%$ & $0.06 \%$ & $0.06 \%$ & $0.06 \%$ \\
& Std. Dev. & $2.73 \%$ & $2.39 \%$ & $2.28 \%$ & $2.29 \%$ & $2.12 \%$ & $2.06 \%$ \\
\hline
\end{tabular}




\section{Table 2: Summary Statistics of Crude Oil Options - Calls}

This table reports summary statistics on call options. Moneyness is defined as $m_{t}=K / F_{t}$, where, $K$ is the strike price and $F_{t}$ is the underlying futures price. Using this definition, we categorize, on each day, options into five moneyness categories: Deep in-the-money (DITM) with $m \leq 0.9$; In-the-money (ITM) with $0.9<m \leq 0.97$; Nearthe-money (NTM) with $0.97<m \leq 1.03$; Out-of-the-money (OTM) with $1.03<m \leq 1.1$, and Deep out-of-themoney (DOTM) with $m>1.1$. EXP represents the expiration of the options. The four expiration categories are: 1 (eight to 30 days), 2 (30-60 days), 3 (60-180 days, and 4 (more than 180 days).

\begin{tabular}{crrrrrr}
\hline Moneyness & EXP & Obs & Days & Price & Return & $\sigma^{\text {imp }}$ \\
\hline DITM & 1 & 41241 & 19.1 & 19.07 & $1.26 \%$ & $57.9 \%$ \\
& 2 & 49838 & 45.5 & 19.77 & $0.99 \%$ & $49.3 \%$ \\
& 3 & 147144 & 114.6 & 21.80 & $0.85 \%$ & $43.9 \%$ \\
ITM & 4 & 199536 & 383.3 & 24.70 & $0.60 \%$ & $38.1 \%$ \\
& 1 & 15377 & 19.0 & 5.90 & $1.72 \%$ & $38.0 \%$ \\
& 2 & 19235 & 45.6 & 7.02 & $0.82 \%$ & $37.3 \%$ \\
& 3 & 66553 & 116.9 & 8.77 & $1.04 \%$ & $35.2 \%$ \\
NTM & 4 & 86817 & 361.3 & 11.71 & $0.80 \%$ & $31.2 \%$ \\
& 1 & 13692 & 19.1 & 2.55 & $-0.86 \%$ & $36.4 \%$ \\
& 2 & 17416 & 45.7 & 3.98 & $-0.22 \%$ & $36.3 \%$ \\
OTM & 3 & 61887 & 117.2 & 6.03 & $0.15 \%$ & $34.8 \%$ \\
& 4 & 82272 & 357.1 & 9.11 & $0.22 \%$ & $30.9 \%$ \\
& 1 & 14955 & 19.6 & 0.96 & $-8.71 \%$ & $36.9 \%$ \\
DOTM & 2 & 20146 & 45.7 & 2.05 & $-2.05 \%$ & $35.9 \%$ \\
& 3 & 61653 & 114.5 & 3.92 & $-0.70 \%$ & $34.8 \%$ \\
& 4 & 73602 & 362.2 & 7.36 & $-0.24 \%$ & $31.3 \%$ \\
& 1 & 15723 & 22.8 & 0.44 & $-15.20 \%$ & $50.9 \%$ \\
& 2 & 51367 & 46.8 & 0.68 & $-7.35 \%$ & $44.7 \%$ \\
& 3 & 212729 & 115.3 & 1.40 & $-3.29 \%$ & $41.5 \%$ \\
& 4 & 316620 & 386.7 & 3.10 & $-0.99 \%$ & $35.2 \%$ \\
\hline
\end{tabular}




\section{Table 3: Summary Statistics of Crude Oil Options - Puts}

This table reports summary statistics on the put options. Moneyness is defined as $m_{t}=F_{t} / K$, where, $K$ is the strike price and $F_{t}$ is the underlying futures price. Using this definition, we categorize options, on each day, into five moneyness categories: Deep in-the-money (DITM) with $m \leq 0.9$; In-the-money (ITM) with $0.9<m \leq 0.97$; Nearthe-money (NTM) with $0.97<m \leq 1.03$; Out-of-the-money (OTM) with $1.03<m \leq 1.1$, and Deep out-of-themoney (DOTM) with $m>1.1$. EXP represents the expiration of the options. The four expiration categories are: 1 (eight to 30 days), 2 (30-60 days), 3 (60-180 days, and 4 (more than 180 days).

\begin{tabular}{ccrrrrr}
\hline Moneyness & Exp & \multicolumn{1}{c}{ Obs } & Days & Price & Return & $\sigma^{\text {imp }}$ \\
\hline DITM & 1 & 32719 & 19.5 & 26.13 & $1.34 \%$ & $63.6 \%$ \\
& 2 & 41654 & 45.4 & 32.70 & $1.16 \%$ & $60.6 \%$ \\
& 3 & 110649 & 113.0 & 33.29 & $0.99 \%$ & $51.7 \%$ \\
& 4 & 177954 & 402.8 & 36.32 & $0.37 \%$ & $38.1 \%$ \\
ITM & 1 & 13808 & 19.1 & 6.05 & $1.31 \%$ & $37.7 \%$ \\
& 2 & 15978 & 45.5 & 7.13 & $1.15 \%$ & $37.2 \%$ \\
& 3 & 47355 & 115.8 & 9.20 & $1.10 \%$ & $36.8 \%$ \\
NTM & 4 & 59104 & 366.3 & 12.79 & $0.60 \%$ & $32.8 \%$ \\
& 1 & 13458 & 19.1 & 2.57 & $-3.67 \%$ & $36.6 \%$ \\
& 2 & 16853 & 45.7 & 3.98 & $-0.91 \%$ & $36.4 \%$ \\
OTM & 3 & 58917 & 117.5 & 6.01 & $-0.25 \%$ & $35.1 \%$ \\
& 4 & 78859 & 359.1 & 9.05 & $-0.05 \%$ & $31.3 \%$ \\
& 1 & 13437 & 19.5 & 0.99 & $-11.73 \%$ & $38.5 \%$ \\
DOTM & 2 & 17993 & 45.7 & 2.09 & $-3.15 \%$ & $37.3 \%$ \\
& 3 & 63773 & 117.2 & 3.92 & $-1.50 \%$ & $35.3 \%$ \\
& 4 & 86873 & 363.1 & 6.95 & $-0.70 \%$ & $31.4 \%$ \\
& 2 & 13632 & 22.5 & 0.45 & $-14.34 \%$ & $51.0 \%$ \\
& 3 & 218649 & 46.8 & 0.70 & $-6.75 \%$ & $45.0 \%$ \\
& 4 & 360751 & 369.8 & 2.91 & $-0.91 \%$ & $35.2 \%$ \\
\hline
\end{tabular}




\section{Table 4: Summary Statistics of Crude Oil Inventory Announcements}

This table reports the summary statistics on EIA crude oil inventory changes. Survey is the median value from each weekly Bloomberg survey. Actual is the realized value. Surprise is the difference between actual and survey. The standardized surprise (Std. Surp.) is the surprise standardized by the unconditional standard deviation of the sample. The column "News" indicates all news, or positive or negative inventory surprise subgroups.

\begin{tabular}{|c|c|c|c|c|c|c|}
\hline News & Obs & Statistics & Survey & Actual & Surprise & Std. Surp. \\
\hline \multicolumn{7}{|c|}{ Panel A: Overall Sample } \\
\hline All & 446 & $\begin{array}{l}\text { Min } \\
\text { Max } \\
\text { Mean } \\
\text { Std. Dev. }\end{array}$ & $\begin{array}{r}-7700.00 \\
3200.00 \\
187.62 \\
1622.85\end{array}$ & $\begin{array}{r}-10570.00 \\
9390.00 \\
112.34 \\
3474.90\end{array}$ & $\begin{array}{r}-9597.00 \\
9033.00 \\
-75.28 \\
3040.70\end{array}$ & $\begin{array}{r}-3.16 \\
2.97 \\
-0.02 \\
1.00\end{array}$ \\
\hline \multicolumn{7}{|c|}{ Panel B: Subsamples Divided by Negative and Positive Inventory Surprises } \\
\hline Negative & 223 & $\begin{array}{l}\text { Min } \\
\text { Max } \\
\text { Mean } \\
\text { Std. Dev. }\end{array}$ & $\begin{array}{r}-7000.00 \\
3200.00 \\
168.99 \\
1671.62\end{array}$ & $\begin{array}{r}-10570.00 \\
2844.00 \\
-2284.88 \\
2655.69\end{array}$ & $\begin{array}{r}-9597.00 \\
0.00 \\
-2453.87 \\
1987.27\end{array}$ & $\begin{array}{r}-3.16 \\
0.00 \\
-0.81 \\
0.65\end{array}$ \\
\hline Positive & 223 & $\begin{array}{l}\text { Min } \\
\text { Max } \\
\text { Mean } \\
\text { Std. Dev. }\end{array}$ & $\begin{array}{r}-7700.00 \\
3000.00 \\
206.24 \\
1576.11 \\
\end{array}$ & $\begin{array}{r}-6453.00 \\
9390.00 \\
2509.56 \\
2367.81 \\
\end{array}$ & $\begin{array}{r}11.00 \\
9033.00 \\
2303.31 \\
1793.80 \\
\end{array}$ & $\begin{array}{l}0.00 \\
2.97 \\
0.76 \\
0.59 \\
\end{array}$ \\
\hline
\end{tabular}




\section{Table 5: Macroeconomic News and Other Variables}

This table reports the 29 macroeconomic news and 3 petroleum related news variables used in this study. The table includes their full names, Bloomberg Tickers, variable names used in the regressions and total numbers of observations during the sample period.

\begin{tabular}{|c|c|c|c|}
\hline Name & Bloomberg Ticker & Variable Name & Count \\
\hline \multicolumn{4}{|l|}{ Macroeconomic Announcements } \\
\hline Budget Deficit & FDDSSD Index & FDDSSD & 102 \\
\hline Building Permits & NHSPATOT Index & NHSPATOT & 102 \\
\hline Business Inventories & MTIBCHNG Index & MTIBCHNG & 101 \\
\hline Capacity Utilization & CPTICHNG Index & CPTICHNG & 102 \\
\hline Change in Nonfarm Payrolls & NFP TCH Index & NFP & 102 \\
\hline Chicago Purchasing Manager & CHPMINDX Index & CHPMINDX & 103 \\
\hline Construction Spending MoM & CNSTTMOM Index & CNSTTMOM & 101 \\
\hline Consumer Confidence Index & CONCCONF Index & CONCCONF & 103 \\
\hline Consumer Credit & CICRTOT Index & CICRTOT & 101 \\
\hline Consumer Price Index & CPI YOY Index & CPI & 103 \\
\hline Durable Goods Orders & DGNOCHNG Index & DGNOCHNG & 102 \\
\hline Existing Home Sales & ETSLTOTL Index & ETSLTOTL & 82 \\
\hline FOMC Rate Decision (Upper Bound) & FDTR Index & FDTR & 69 \\
\hline Factory Orders & TMNOCHNG Index & TMNOCHNG & 101 \\
\hline GDP & GDP PIQQ Index & GDP & 103 \\
\hline Housing Starts & NHSPSTOT Index & NHSPSTOT & 102 \\
\hline ISM Manufacturing & NAPMPMI Index & NAPMPMI & 102 \\
\hline ISM Prices Paid & NAPMPRIC Index & NAPMPRIC & 102 \\
\hline Import Price Index MoM & IMP1CHNG Index & IMP1CHNG & 102 \\
\hline Industrial Production MoM & IP CHNG Index & IP & 102 \\
\hline Initial Jobless Claims & INJCJC Index & INJCJC & 446 \\
\hline Leading Index & LEI CHNG Index & LEI & 102 \\
\hline New Home Sales & NHSLTOT Index & NHSLTOT & 102 \\
\hline Personal Income & PITLCHNG Index & PITLCHNG & 102 \\
\hline Producer Price Index & PPI CHNG Index & PPI & 102 \\
\hline Retail Sales Advance MoM & RSTAMOM Index & RSTAMOM & 102 \\
\hline Trade Balance & USTBTOT Index & USTBTOT & 101 \\
\hline U. of Mich. Sentiment & CONSSENT Index & CONSSENT & 103 \\
\hline Unemployment Rate & USURTOT Index & USURTOT & 102 \\
\hline \multicolumn{4}{|c|}{ Announcements from the EIA Petroleum Report } \\
\hline Natural Gas Inventory Change & DOENUSCH Index & DOENUSCH & 446 \\
\hline Gasoline Inventory Change & DOEASMGS INDEX & DOEASMGS & 415 \\
\hline Distillate Fuel Oil Inventory Change & DOESDIST INDEX & DOESDIST & 442 \\
\hline
\end{tabular}


Table 6: Daily Crude Oil Futures Returns and Volume

This table presents mean returns (in percentage) and volume (in thousands) of crude oil futures for the six nearest dated contracts. Days $[-2,+2]$ refer to the days surrounding the inventory announcement day, Day 0.

\begin{tabular}{lcrrrr|rrrrr}
\hline \multirow{2}{*}{ Contract } & \multicolumn{7}{c|}{ Positive Shocks } & \multicolumn{5}{c}{ Negative Shocks } \\
\cline { 2 - 11 } & \multicolumn{1}{c}{-2} & \multicolumn{1}{c|}{0} & \multicolumn{1}{c|}{+1} & \multicolumn{1}{c}{+2} & \multicolumn{1}{c}{-1} & 0 & +1 & +2 \\
\hline Panel A: Returns & & & & & & & & & \\
CL1 & 0.21 & -0.48 & -0.17 & 0.19 & 0.14 & -0.43 & 0.14 & 0.56 & 0.09 & 0.18 \\
CL2 & 0.14 & -0.33 & -0.21 & 0.21 & 0.14 & -0.44 & 0.10 & 0.51 & 0.12 & 0.19 \\
CL3 & 0.14 & -0.30 & -0.16 & 0.21 & 0.12 & -0.40 & 0.08 & 0.48 & 0.10 & 0.20 \\
CL4 & 0.14 & -0.37 & -0.02 & 0.21 & 0.11 & -0.38 & 0.07 & 0.44 & 0.09 & 0.19 \\
CL5 & 0.14 & -0.25 & -0.10 & 0.21 & 0.10 & -0.35 & 0.05 & 0.42 & 0.08 & 0.18 \\
CL6 & 0.14 & -0.23 & -0.10 & 0.23 & 0.09 & -0.33 & 0.03 & 0.42 & 0.08 & 0.16 \\
Panel B: Volume & & & & & & & & & \\
CL1 & 189.97 & 192.16 & 216.15 & 218.98 & 214.80 & 205.65 & 205.84 & 223.22 & 226.44 & 205.73 \\
CL2 & 99.59 & 105.16 & 105.17 & 113.43 & 109.24 & 104.82 & 109.64 & 115.54 & 120.33 & 111.13 \\
CL3 & 34.64 & 35.25 & 37.39 & 41.25 & 39.76 & 37.38 & 37.96 & 40.85 & 43.74 & 40.24 \\
CL4 & 17.28 & 17.57 & 19.16 & 21.33 & 20.47 & 17.66 & 16.97 & 19.06 & 20.49 & 20.54 \\
CL5 & 9.28 & 9.17 & 10.39 & 11.33 & 10.41 & 11.19 & 10.82 & 11.94 & 12.62 & 12.05 \\
CL6 & 7.43 & 7.24 & 7.56 & 7.91 & 8.07 & 8.49 & 8.08 & 9.19 & 9.55 & 9.49 \\
\hline
\end{tabular}




\section{Table 7: Call Option Returns Surrounding Inventory Announcement}

The table presents the mean returns of call options for different time-to-maturity and moneyness categories. The four time-to-maturity categories are: 1 (eight to 30 days), 2 (30-60 days), 3 (60-180 days, and 4 (more than 180 days). Moneyness is defined as $m_{t}=F_{t} / K$, where, $K$ is the strike price and $F_{t}$ is the underlying futures price. Using this definition we categorize options, on each day, into five moneyness categories: Deep in-the-money (DITM) with $m \leq 0.9$; In-the-money (ITM) with $0.9<m \leq 0.97$; Near-the-money (NTM) with $0.97<m \leq 1.03$; Out-of-the-money (OTM) with $1.03<m \leq 1.1$, and Deep out-of-the-money (DOTM) with $m>1.1$. Positive and negative shocks refer to positive/negative inventory change surprises, respectively. Days [-2, +2$]$ refer to the days surrounding the inventory announcement day, Day 0.

\begin{tabular}{|c|c|c|c|c|c|c|c|c|c|c|c|}
\hline \multirow{2}{*}{ Moneyness } & \multirow{2}{*}{ EXP } & \multicolumn{5}{|c|}{ Positive Shocks } & \multicolumn{5}{|c|}{ Negative Shocks } \\
\hline & & -2 & -1 & 0 & +1 & +2 & -2 & -1 & 0 & +1 & +2 \\
\hline \multirow[t]{4}{*}{ DITM } & 1 & 2.24 & -0.93 & -1.23 & 1.61 & 1.53 & -0.23 & 0.87 & 3.26 & 2.60 & 3.28 \\
\hline & 2 & 0.93 & -1.08 & -0.11 & 1.52 & 1.02 & -0.07 & 1.37 & 3.30 & 2.12 & 1.49 \\
\hline & 3 & 1.35 & -0.83 & 0.04 & 1.22 & 1.03 & -0.24 & 0.49 & 2.28 & 1.44 & 1.66 \\
\hline & 4 & 0.96 & -0.34 & 0.16 & 0.80 & 0.63 & 0.05 & 0.48 & 1.64 & 0.60 & 1.00 \\
\hline \multirow[t]{4}{*}{ ITM } & 1 & 3.29 & -2.64 & -2.00 & 2.14 & 2.29 & -2.36 & 1.14 & 6.34 & 5.01 & 4.15 \\
\hline & 2 & 1.45 & -2.15 & -1.21 & 1.56 & 1.30 & -2.03 & 1.70 & 5.08 & 2.26 & 0.86 \\
\hline & 3 & 1.79 & -0.90 & -0.40 & 1.85 & 1.32 & -0.72 & 1.19 & 3.15 & 1.72 & 1.29 \\
\hline & 4 & 1.50 & -0.37 & 0.18 & 1.45 & 0.87 & -0.10 & 0.84 & 1.89 & 0.73 & 0.90 \\
\hline \multirow[t]{4}{*}{ NTM } & 1 & 0.66 & -6.23 & -5.74 & 0.01 & 1.11 & -9.08 & -1.52 & 6.18 & 3.50 & 2.56 \\
\hline & 2 & 0.38 & -3.53 & -2.66 & 1.14 & 0.46 & -4.68 & 0.94 & 5.44 & 1.13 & 0.10 \\
\hline & 3 & 0.79 & -1.94 & -1.20 & 1.03 & 0.38 & -2.14 & 0.63 & 2.75 & 0.83 & 0.19 \\
\hline & 4 & 0.75 & -0.85 & -0.18 & 0.83 & 0.33 & -1.09 & 0.24 & 1.62 & 0.18 & 0.22 \\
\hline \multirow[t]{4}{*}{ OTM } & 1 & -8.20 & -14.65 & -14.45 & -6.68 & -4.48 & -21.61 & -7.74 & -0.91 & -4.45 & -2.72 \\
\hline & 2 & -1.60 & -5.54 & -5.16 & -0.05 & -1.06 & -7.88 & -0.05 & 4.63 & -0.88 & -1.88 \\
\hline & 3 & 0.24 & -2.61 & -2.17 & 0.17 & -0.82 & -3.68 & 0.09 & 2.35 & -0.46 & -0.39 \\
\hline & 4 & 0.29 & -1.04 & -0.73 & 0.35 & -0.41 & -1.85 & 0.21 & 1.25 & -0.58 & -0.11 \\
\hline \multirow[t]{4}{*}{ DOTM } & 1 & -15.85 & -21.36 & -20.48 & -10.84 & -14.44 & -32.93 & -5.75 & -7.20 & -17.59 & -5.54 \\
\hline & 2 & -9.55 & -9.60 & -11.50 & -4.75 & -7.78 & -15.71 & -2.88 & 0.57 & -6.07 & -4.26 \\
\hline & 3 & -3.48 & -4.67 & -5.13 & -2.12 & -4.32 & -8.27 & -0.46 & 0.55 & -3.12 & -2.34 \\
\hline & 4 & -0.76 & -1.59 & -1.45 & 0.24 & -2.06 & -3.63 & 0.30 & 0.96 & -1.59 & -0.56 \\
\hline
\end{tabular}




\section{Table 8: Put Option Returns Surrounding Inventory Announcement}

The table presents the mean returns of put options for different time-to-maturity and moneyness categories. The four time-to-maturity categories are: 1 (eight to 30 days), 2 (30-60 days), 3 (60-180 days, and 4 (more than 180 days). Moneyness is defined as $m_{t}=F_{t} / K$, where, $K$ is the strike price and $F_{t}$ is the underlying futures price. Using this definition, we categorize options, on each day, into five moneyness categories: Deep in-the-money (DITM) with $m \leq 0.9$; In-the-money (ITM) with $0.9<m \leq 0.97$; Near-the-money (NTM) with $0.97<m \leq 1.03$; Out-of-the-money (OTM) with $1.03<m \leq 1.1$, and Deep out-of-the-money (DOTM) with $m>1.1$. Positive and negative shocks refer to positive/negative inventory change surprises, respectively. Days [-2,+2] refer to the days surrounding the inventory announcement day, Day 0.

\begin{tabular}{|c|c|c|c|c|c|c|c|c|c|c|c|}
\hline \multirow{2}{*}{ Moneyness } & \multirow{2}{*}{ EXP } & \multicolumn{5}{|c|}{ Positive Shocks } & \multicolumn{5}{|c|}{ Negative Shocks } \\
\hline & & -2 & -1 & 0 & +1 & +2 & -2 & -1 & 0 & +1 & +2 \\
\hline \multirow[t]{4}{*}{ DITM } & 1 & 1.13 & 2.34 & 2.07 & 0.58 & 0.89 & 5.29 & 0.38 & -0.74 & 2.12 & 0.09 \\
\hline & 2 & 0.59 & 1.55 & 1.88 & -0.62 & 2.16 & 4.47 & 0.51 & -0.58 & 1.10 & 0.59 \\
\hline & 3 & 0.21 & 1.88 & 1.11 & -0.24 & 1.90 & 3.44 & 0.83 & -0.77 & 1.50 & 0.28 \\
\hline & 4 & -0.01 & 0.89 & 0.19 & -0.58 & 0.76 & 1.83 & 0.55 & -0.73 & 0.57 & 0.47 \\
\hline \multirow[t]{4}{*}{ ITM } & 1 & -0.65 & 4.24 & 3.51 & 2.21 & -0.69 & 5.13 & 2.74 & -1.93 & -0.84 & -0.31 \\
\hline & 2 & -0.85 & 2.83 & 2.63 & 0.15 & 1.80 & 4.43 & 0.71 & -2.14 & 0.45 & 1.63 \\
\hline & 3 & -0.44 & 2.22 & 1.61 & 1.00 & 1.70 & 3.22 & 0.80 & -0.70 & 1.27 & 0.83 \\
\hline & 4 & -0.23 & 1.31 & 0.66 & 0.24 & 0.90 & 2.02 & 0.27 & -0.35 & 1.07 & 0.44 \\
\hline \multirow[t]{4}{*}{ NTM } & 1 & -8.13 & 3.01 & 0.22 & -2.36 & -6.06 & -1.55 & -0.70 & -8.70 & -6.88 & -5.00 \\
\hline & 2 & -3.27 & 2.93 & 0.69 & -1.49 & -1.66 & 1.76 & -1.08 & -5.15 & -1.57 & -0.50 \\
\hline & 3 & -1.53 & 1.85 & 0.45 & -0.73 & -0.64 & 1.23 & 0.06 & -2.17 & -0.73 & 0.06 \\
\hline & 4 & -0.77 & 1.06 & -0.04 & -0.66 & 0.03 & 0.85 & -0.02 & -0.88 & -0.11 & 0.41 \\
\hline \multirow[t]{4}{*}{ OTM } & 1 & -18.11 & -1.61 & -7.92 & -10.57 & -13.74 & -11.99 & -7.63 & -16.68 & -15.22 & -12.92 \\
\hline & 2 & -6.54 & 1.81 & -1.01 & -3.77 & -3.68 & -0.78 & -3.12 & -7.94 & -3.64 & -2.68 \\
\hline & 3 & -3.12 & 1.09 & -0.56 & -1.95 & -2.03 & -0.20 & -1.13 & -3.50 & -1.83 & -1.50 \\
\hline & 4 & -1.60 & 0.58 & -0.55 & -1.29 & -0.60 & -0.05 & -0.71 & -1.37 & -0.81 & -0.30 \\
\hline \multirow[t]{4}{*}{ DOTM } & 1 & -22.90 & -9.12 & -11.47 & -14.65 & -13.25 & -13.52 & -15.43 & -14.87 & -9.68 & -17.54 \\
\hline & 2 & -11.22 & -1.56 & -5.04 & -8.08 & -5.85 & -5.00 & -7.74 & -9.56 & -7.00 & -5.28 \\
\hline & 3 & -5.94 & 0.27 & -1.83 & -2.84 & -3.12 & -1.74 & -2.07 & -4.49 & -2.88 & -2.31 \\
\hline & 4 & -2.13 & 0.75 & -0.90 & -1.28 & -0.84 & -0.58 & -0.57 & -1.69 & -1.19 & -0.44 \\
\hline
\end{tabular}




\section{Table 9: Futures Market Regressions}

This table reports the results of the regression: $R_{t}=\alpha+\sum_{i=1}^{3} \beta_{i} R_{t-i}+\gamma_{0} S S I_{t}+\varepsilon_{t}$, for the six continuous crude oil futures contracts (CL1-CL6). Here, $R_{t}$ refers to the daily return of crude oil futures, $R_{t-i}$ is the $\mathrm{i}^{\text {th }}$ lagged daily return of crude oil futures, and $S S I_{t}=\left(A_{t}-E_{t}\right) / \sigma$ refers to the standardized surprise of crude oil inventory on day $\mathrm{t}$ (zero if there is no inventory news on day $\mathrm{t}$ ).

\begin{tabular}{lcccccc}
\hline & CL1 & CL2 & CL3 & CL4 & CL5 & CL6 \\
\hline$\alpha$ & 0.058 & 0.054 & 0.056 & 0.062 & 0.059 & 0.058 \\
& {$[1.00]$} & {$[1.06]$} & {$[1.15]$} & {$[1.26]$} & {$[1.31]$} & {$[1.31]$} \\
$R_{t-1}$ & $-.110^{* * *}$ & $-.073^{* * *}$ & $-.067^{* * *}$ & $-.100^{* * *}$ & $-.062^{* * *}$ & $-.061^{* * *}$ \\
& {$[-5.14]$} & {$[-3.39]$} & {$[-3.11]$} & {$[-4.63]$} & {$[-2.90]$} & {$[-2.82]$} \\
$R_{t-2}$ & $-.068^{* * *}$ & -0.03 & -0.026 & $-.036^{*}$ & -0.022 & -0.017 \\
& {$[-3.14]$} & {$[-1.38]$} & {$[-1.23]$} & {$[-1.65]$} & {$[-1.02]$} & {$[-0.80]$} \\
$R_{t-3}$ & $0.045^{* *}$ & $0.038^{*}$ & $0.039^{*}$ & $0.036^{*}$ & $0.044^{* *}$ & $0.044^{* *}$ \\
& {$[2.09]$} & {$[1.78]$} & {$[1.83]$} & {$[1.69]$} & {$[2.04]$} & {$[2.03]$} \\
$S S I_{t}$ & $-.482^{* * *}$ & $-.460^{* * *}$ & $-.416^{* *}$ & $-.332^{* * *}$ & $-.349^{* * *}$ & $-.342^{* * *}$ \\
& {$[-3.77]$} & {$[-4.09]$} & {$[-3.88]$} & {$[-3.08]$} & {$[-3.49]$} & {$[-3.53]$} \\
\multirow{2}{*}{ Adj- $R^{2}$} & 0.022 & 0.012 & 0.011 & 0.014 & 0.009 & 0.009 \\
\hline \multicolumn{6}{c}{} & \multicolumn{7}{c}{}
\end{tabular}




\section{Table 10: Futures Market Regressions with Additional Factors}

This table reports the results of the regression: $R_{t}=\alpha+\sum_{i=1}^{3} \beta_{i} R_{t-i}+\gamma_{0} S S I_{t}+\sum_{k=1}^{32} \theta_{k} S S M_{k t}+\varepsilon_{t}$, for the six continuous crude oil futures contracts. The regression is run with all the 32 additional factors, but only the news with at least one significant parameters at the $10 \%$ level is reported. Here, $R_{t}$ refers to the daily return of crude oil futures, $R_{t-i}$ is the $\mathrm{i}^{\text {th }}$ lagged daily return of the crude oil futures, $S S I_{t}=\left(A_{t}-E_{t}\right) / \sigma$ refers to the standardized surprise of crude oil inventory on day $\mathrm{t}$ (zero if there is no inventory news on day $\mathrm{t}$ ), and $S S M_{k t}$ refers to the standardized surprise of the $k^{\text {th }}$ news variable on day $t$. If there is no release of the $k^{\text {th }}$ news variable, $S S M_{k t}=0$. Here, $1 \leq k \leq 32$, refers to all of the 29 macroeconomic news announcements plus three other storage releases from the EIA report (gasoline, natural gas, and distillate fuel).

\begin{tabular}{|c|c|c|c|c|c|c|}
\hline & CL1 & CL2 & CL3 & CL4 & CL5 & CL6 \\
\hline \multirow[t]{2}{*}{$\alpha$} & 0.087 & 0.084 & $0.083^{*}$ & 0.078 & $0.077^{*}$ & $0.075^{*}$ \\
\hline & {$[1.48]$} & {$[1.61]$} & {$[1.65]$} & {$[1.58]$} & {$[1.65]$} & [1.69] \\
\hline \multirow[t]{2}{*}{$R_{t-1}$} & $-.102^{3 * *}$ & $-.081^{* * * *}$ & $-.081^{* * *}$ & $-.070^{* * *}$ & $-.072^{* * *}$ & $-.063^{3 * *}$ \\
\hline & {$[-4.94]$} & {$[-3.93]$} & {$[-3.92]$} & {$[-3.48]$} & {$[-3.47]$} & {$[-3.00]$} \\
\hline \multirow[t]{2}{*}{$R_{t-2}$} & $-.072^{* * *}$ & -0.024 & -0.021 & -0.021 & -0.008 & -0.005 \\
\hline & {$[-3.44]$} & {$[-1.13]$} & {$[-1.00]$} & {$[-1.00]$} & {$[-0.36]$} & {$[-0.21]$} \\
\hline \multirow[t]{2}{*}{$R_{t-3}$} & $0.045^{* *}$ & $0.035^{*}$ & $0.044^{* *}$ & 0.027 & $0.049^{* *}$ & $0.049^{* *}$ \\
\hline & {$[2.26]$} & [1.65] & {$[2.08]$} & [1.49] & {$[2.32]$} & {$[2.30]$} \\
\hline \multirow[t]{2}{*}{$S S I_{t}$} & $-.542^{\vec{*} * *}$ & $-.516^{* * * *}$ & $-.472^{* * *}$ & $-.408^{* * * *}$ & $-.372^{* * *}$ & $-.377^{* * *}$ \\
\hline & {$[-4.31]$} & {$[-4.66]$} & {$[-4.45]$} & {$[-3.90]$} & [-3.79] & {$[-3.94]$} \\
\hline \multirow[t]{2}{*}{ INJCJC } & $-.391^{* * * *}$ & $-.288^{* * * *}$ & $-.280^{* * * *}$ & $-.345^{* * *}$ & $-.325^{* * * *}$ & $-.318^{* * *}$ \\
\hline & {$[-3.11]$} & {$[-2.62]$} & {$[-2.71]$} & {$[-3.42]$} & {$[-3.42]$} & {$[-3.39]$} \\
\hline \multirow[t]{2}{*}{ CPI } & -0.162 & $-.381^{*}$ & -0.330 & -0.205 & -0.253 & -0.267 \\
\hline & {$[-0.61]$} & {$[-1.79]$} & {$[-1.51]$} & {$[-0.93]$} & {$[-1.24]$} & {$[-1.38]$} \\
\hline \multirow[t]{2}{*}{ NAPMPMI } & $-.420^{*}$ & $-.570^{* * * *}$ & $-.655^{* * *}$ & $-.597^{* * *}$ & $-.604^{* * *}$ & $-.505^{* *}$ \\
\hline & {$[-1.85]$} & {$[-2.71]$} & {$[-3.20]$} & {$[-2.90]$} & {$[-2.99]$} & {$[-2.57]$} \\
\hline \multirow[t]{2}{*}{ NAPMPRIC } & $0.651^{* * *}$ & $0.633^{* * *}$ & $0.656^{* * *}$ & $0.677^{* * *}$ & $0.722^{* * *}$ & $0.693^{* * *}$ \\
\hline & [3.19] & {$[3.40]$} & [3.62] & [3.63] & [3.93] & {$[3.86]$} \\
\hline \multirow[t]{2}{*}{ IMP1CHNG } & -0.401 & $-.391^{*}$ & $-.479^{* *}$ & $-.431^{* *}$ & -0.304 & $-.386^{*}$ \\
\hline & {$[-1.52]$} & {$[-1.71]$} & {$[-2.14]$} & {$[-1.96]$} & {$[-1.45]$} & {$[-1.95]$} \\
\hline \multirow[t]{2}{*}{ CPTICHNG } & $0.629^{*}$ & $0.668^{*}$ & $0.677^{* *}$ & 0.492 & $0.582^{*}$ & $0.619^{* *}$ \\
\hline & {$[1.65]$} & {$[1.79]$} & {$[2.06]$} & {$[1.42]$} & {$[1.82]$} & {$[2.03]$} \\
\hline \multirow[t]{2}{*}{ DOEASMGS } & $-.289^{* *}$ & $-.313^{* * *}$ & $-.306^{* * *}$ & $-.310^{* * *}$ & $-.302^{* * * *}$ & $-.310^{* * *}$ \\
\hline & {$[-2.19]$} & {$[-2.72]$} & {$[-2.79]$} & {$[-2.88]$} & [-2.99] & {$[-3.14]$} \\
\hline \multirow[t]{2}{*}{ DOESDIST } & $-.210^{*}$ & $-.214^{*}$ & $-.230^{* * \sqrt[*]{*}}$ & $-.225^{* * \sqrt[*]{*}}$ & $-.205^{* *}$ & $-.193^{* *}$ \\
\hline & {$[-1.67]$} & {$[-1.95]$} & {$[-2.15]$} & {$[-2.18]$} & {$[-2.14]$} & {$[-2.05]$} \\
\hline \multirow[t]{2}{*}{ LEI } & -0.339 & $-.462^{* * * 3}$ & $-.408^{*}$ & $-.425^{* * * 3}$ & $-.458^{* *}$ & $-.426^{* *}$ \\
\hline & {$[-1.28]$} & {$[-2.10]$} & {$[-1.92]$} & {$[-1.98]$} & {$[-2.23]$} & {$[-2.15]$} \\
\hline \multirow[t]{2}{*}{ DGNOCHNG } & $-.515^{* *}$ & $-.481^{* *}$ & $-.501^{* * *}$ & $-.482^{* *}$ & $-.552^{* * *}$ & $-.422^{* *}$ \\
\hline & {$[-2.10]$} & {$[-2.37]$} & {$[-2.59]$} & {$[-2.56]$} & {$[-3.20]$} & {$[-2.45]$} \\
\hline \multirow[t]{2}{*}{ CNSTTMOM } & $0.464^{* *}$ & $0.443^{* *}$ & $0.504^{* * *}$ & $0.479^{* *}$ & $0.572^{* * *}$ & $0.486^{* * *}$ \\
\hline & {$[2.05]$} & {$[2.18]$} & {$[2.73]$} & {$[2.53]$} & [3.27] & {$[2.75]$} \\
\hline \multirow[t]{2}{*}{ TMNOCHNG } & -0.370 & $-.484^{* *}$ & $-.510^{* * * *}$ & $-.569^{* * *}$ & $-.542^{* * *}$ & $-.512^{* * *}$ \\
\hline & {$[-1.61]$} & {$[-2.42]$} & {$[-2.74]$} & {$[-3.29]$} & {$[-3.04]$} & {$[-2.85]$} \\
\hline \multirow[t]{2}{*}{ ETSLTOTL } & 0.379 & $0.492^{*}$ & $0.469^{*}$ & $0.502^{*}$ & $0.453^{*}$ & $0.443^{*}$ \\
\hline & [1.38] & {$[1.84]$} & {$[1.80]$} & [1.91] & [1.82] & {$[1.84]$} \\
\hline $\operatorname{Adj}-R^{2}$ & 0.039 & 0.040 & 0.045 & 0.041 & 0.048 & 0.043 \\
\hline
\end{tabular}




\section{Table 11: Futures Market Asymmetric Regressions}

This table reports the results of the asymmetric regressions for the six continuous crude oil futures contracts (CL-CL6). In the regressions, $R_{t}$ refers to the daily return of crude oil futures, $R_{t-i}$ is the $\mathrm{i}^{\text {th }}$ lagged daily return of crude oil futures, $S S I_{t}^{+}$and $S S I_{t}^{-}$refer to the positive and negative standardized surprises. That is, we classify the standardized surprises in such a way that if the surprise $S S I_{t}$ is positive then $S S I_{t}^{+}=S S I_{t}$, and $S S I_{t}^{-}=0$; otherwise, $S S I_{t}^{-}=$ $S S I_{t}$, and $S S I_{t}^{+}=0$. They are both zeros when there is no inventory announcement on day $\mathrm{t}$, and $S S M_{k t}$ refers to the standardized surprise of the $k^{t h}$ news variable on day $t$. If there is no release of the $k^{\text {th }}$ news variable, $S S M_{k t}=0$. Here, $1 \leq k \leq 32$, refers to all of the 29 macroeconomic news announcements plus three other storage releases from the EIA report (gasoline, natural gas, and distillate fuel).

\begin{tabular}{|c|c|c|c|c|c|c|}
\hline & CL1 & CL2 & CL3 & CL4 & CL5 & CL6 \\
\hline \multicolumn{7}{|c|}{ Panel A: $R_{t}=\alpha+\sum_{i=1}^{3} \beta_{i} R_{t-i}+\gamma^{+} S S I_{t}^{+}+\gamma^{-} S S I_{t}^{-}+\varepsilon_{t}$} \\
\hline \multirow[t]{2}{*}{$\alpha$} & 0.065 & 0.060 & 0.056 & 0.048 & 0.051 & 0.050 \\
\hline & {$[1.04]$} & {$[1.07]$} & {$[1.06]$} & {$[0.92]$} & {$[1.05]$} & {$[1.06]$} \\
\hline \multirow[t]{2}{*}{$R_{t-1}$} & $-.121^{* * *}$ & $-.087^{* * *}$ & $-.077^{* * *}$ & $-.066^{* * *}$ & $-.065^{* * *}$ & $-.064^{* * *}$ \\
\hline & {$[-5.71]$} & {$[-4.09]$} & {$[-3.63]$} & {$[-3.12]$} & {$[-3.07]$} & {$[-3.01]$} \\
\hline \multirow{2}{*}{$R_{t-2}$} & $-.061^{* * * *}$ & -0.015 & -0.011 & -0.011 & -0.002 & 0.004 \\
\hline & {$[-2.82]$} & {$[-0.70]$} & {$[-0.49]_{* * *}$} & {$[-0.51]$} & {$[-0.09]_{* * *}$} & {$[0.16]_{* * *}$} \\
\hline \multirow[t]{2}{*}{$R_{t-3}$} & $0.052^{* *}$ & $0.052^{* *}$ & $0.058^{* * *}$ & $0.042^{* *}$ & $0.062^{* * *}$ & $0.060^{* * *}$ \\
\hline & {$[2.55]$} & {$[2.45]$} & {$[2.72]$} & {$[2.21]$} & {$[2.92]$} & {$[2.83]$} \\
\hline \multirow{2}{*}{$S S I_{t}^{+}$} & $-.552^{* *}$ & $-.541^{* *}$ & $-.469^{* *}$ & $-.357^{*}$ & $-.356^{*}$ & $-.343^{*}$ \\
\hline & {$[-2.28]$} & {$[-2.55]$} & {$[-2.28]$} & {$[-1.76]$} & {$[-1.95]$} & {$[-1.91]$} \\
\hline \multirow[t]{2}{*}{$S S I_{t}^{-}$} & $-.473^{* *}$ & $-.421^{* *}$ & $-.395^{* *}$ & $-.384^{* *}$ & $-.366^{* *}$ & $-.363^{* *}$ \\
\hline & {$[-2.27]$} & {$[-2.13]$} & {$[-2.24]$} & {$[-2.09]$} & {$[-2.18]$} & {$[-2.22]$} \\
\hline $\operatorname{Adj}-R^{2}$ & 0.023 & 0.012 & 0.011 & 0.007 & 0.009 & 0.009 \\
\hline \multicolumn{7}{|c|}{ Panel B: $R_{t}=\alpha+\sum_{i=1}^{3} \beta_{i} R_{t-i}+\gamma^{+} S S I_{t}^{+}+\gamma^{-} S S I_{t}^{-}+\sum_{k=1}^{32} \theta_{k} S S M_{k t}+\varepsilon_{t}$, } \\
\hline \multirow[t]{2}{*}{$\alpha$} & $0.103^{*}$ & $0.093^{*}$ & 0.084 & 0.076 & 0.074 & 0.071 \\
\hline & {$[1.65]$} & [1.69] & {$[1.58]$} & [1.45] & {$[1.51]$} & [1.49] \\
\hline \multirow[t]{2}{*}{$R_{t-1}$} & $-.106^{* * *}$ & $-.084^{* * *}$ & $-.082^{* * *}$ & $-.077^{* * *}$ & $-.071^{* * *}$ & $-.063^{* * *}$ \\
\hline & {$[-5.16]_{* * *}$} & {$[-4.08]$} & {$[-4.01]$} & {$[-3.86]$} & {$[-3.43]$} & {$[-2.99]$} \\
\hline \multirow[t]{2}{*}{$R_{t-2}$} & $-.071^{* * *}$ & -0.018 & -0.02 & -0.018 & -0.002 & -0.003 \\
\hline & {$[-3.41]$} & {$[-0.83]$} & {$[-0.95]$} & {$[-0.83]$} & {$[-0.09]_{* *}$} & {$[-0.15]_{* *}$} \\
\hline \multirow[t]{2}{*}{$R_{t-3}$} & $0.046^{* *}$ & $0.041^{* *}$ & $0.043^{* *}$ & $0.031^{*}$ & $0.050^{* *}$ & $0.047^{* *}$ \\
\hline & {$[2.37]_{* * *}$} & {$[1.98]_{* * *}$} & {$[2.04]_{* * *}$} & {$[1.79]_{* *}$} & {$[2.36]_{* *}$} & {$[2.24]_{* *}$} \\
\hline \multirow[t]{2}{*}{$S S I_{t}^{+}$} & $-.639^{* * *}$ & $-.600^{* * *}$ & $-.508^{* * * *}$ & $-.400^{* *}$ & $-.364^{* *}$ & $-.352^{* *}$ \\
\hline & {$[-2.94]$} & {$[-2.91]$} & {$[-2.91]$} & {$[-2.06]$} & {$[-2.23]$} & {$[-2.27]$} \\
\hline \multirow[t]{2}{*}{$S S I_{t}^{-}$} & $-.443^{* *}$ & $-.452^{* *}$ & $-.447^{* *}$ & $-.434^{* * *}$ & $-.405^{* *}$ & $-.405^{* *}$ \\
\hline & {$[-2.35]$} & {$[-2.50]$} & {$[-2.57]$} & {$[-2.58]$} & {$[-2.47]$} & {$[-2.54]$} \\
\hline $\operatorname{Adj}-R^{2}$ & 0.039 & 0.036 & 0.044 & 0.041 & 0.040 & 0.040 \\
\hline
\end{tabular}




\section{Table 12: Futures Market Regression with Lag and Lead Inventory Surprises}

This table reports the results of the regression with lag and lead inventory surprises for the six continuous futures contracts. In the regressions, $R_{t}$ refers to the daily return of crude oil futures, $R_{t-i}$ is the $\mathrm{i}^{\text {th }}$ lagged daily return of crude oil futures, $S S I_{t-j}$ is the lag/lead standardized surprise that allows us to investigate news anticipation effects, and $S S M_{k t}$ refers to the standardized surprise of the $k^{t h}$ macroeconomic news on day $t$.

\begin{tabular}{|c|c|c|c|c|c|c|}
\hline & CL1 & CL2 & CL3 & CL4 & CL5 & CL6 \\
\hline \multicolumn{7}{|c|}{ Panel A: $R_{t}=\alpha+\sum_{i=1}^{3} \beta_{i} R_{t-i}+\sum_{j=-2}^{2} \gamma_{j} S S I_{t-j}+\varepsilon_{t}$. } \\
\hline \multirow[t]{2}{*}{$\alpha$} & 0.060 & 0.052 & 0.052 & 0.052 & 0.053 & 0.052 \\
\hline & {$[1.01]$} & {$[0.98]$} & {$[1.04]$} & {$[1.06]$} & {$[1.15]$} & {$[1.15]$} \\
\hline \multirow[t]{2}{*}{$R_{t-1}$} & $-.121^{* * *}$ & $-.086^{* * *}$ & $-.079^{* * *}$ & $-.071^{* * * *}$ & $-.067^{* * *}$ & $-.066^{* * * *}$ \\
\hline & {$[-5.67]$} & {$[-4.01]$} & {$[-3.65]$} & {$[-3.34]$} & {$[-3.14]$} & {$[-3.06]$} \\
\hline \multirow[t]{2}{*}{$R_{t-2}$} & $-.066^{* * *}$ & -0.018 & -0.011 & -0.013 & -0.002 & 0.006 \\
\hline & {$[-3.06]$} & {$[-0.81]$} & {$[-0.49]$} & {$[-0.60]$} & {$[-0.07]$} & {$[0.26]$} \\
\hline \multirow[t]{2}{*}{$R_{t-3}$} & $0.050^{* * *}$ & $0.048^{* * *}$ & $0.056^{* * *}$ & $0.042^{* * *}$ & $0.062^{* * *}$ & $0.062^{* * *}$ \\
\hline & [2.46] & [2.29] & [2.66] & {$[2.15]$} & [2.93] & {$[2.94]$} \\
\hline \multirow{2}{*}{$S S I_{t-2}$} & -0.086 & -0.045 & -0.038 & -0.047 & -0.037 & -0.032 \\
\hline & {$[-0.64]$} & {$[-0.38]$} & {$[-0.33]$} & {$[-0.42]$} & {$[-0.35]$} & {$[-0.31]$} \\
\hline \multirow[t]{2}{*}{$S S I_{t-1}$} & -0.086 & -0.043 & -0.011 & -0.001 & 0.008 & 0.025 \\
\hline & {$[-0.66]$} & {$[-0.37]$} & {$[-0.10]$} & {$[-0.00]$} & {$[0.08]$} & {$[0.25]$} \\
\hline \multirow[t]{2}{*}{$S S I_{t}$} & $-.507^{* * * *}$ & $-.474^{* * * *}$ & $-.426^{* * *}$ & $-.372^{* * * *}$ & $-.360^{* * *}$ & $-.350^{* * *}$ \\
\hline & {$[-3.97]$} & {$[-4.21]$} & {$[-3.98]$} & {$[-3.49]$} & {$[-3.61]$} & {$[-3.62]$} \\
\hline \multirow[t]{2}{*}{$S S I_{t+1}$} & $-.289^{* * *}$ & $-.251^{* *}$ & $-.251^{* * *}$ & $-.276^{* * *}$ & $-.231^{* *}$ & $-.221^{* *}$ \\
\hline & {$[-2.26]$} & {$[-2.23]$} & {$[-2.34]$} & {$[-2.60]$} & {$[-2.33]$} & {$[-2.30]$} \\
\hline \multirow[t]{2}{*}{$S S I_{t+2}$} & $0.310^{* * *}$ & $0.259^{* * *}$ & $0.255^{* *}$ & $0.237^{* *}$ & $0.231^{* *}$ & $0.218^{* * *}$ \\
\hline & {$[2.50]$} & {$[2.40]$} & {$[2.50]$} & {$[2.32]$} & {$[2.41]$} & {$[2.35]$} \\
\hline $\operatorname{Adj}-R^{2}$ & 0.029 & 0.018 & 0.017 & 0.014 & 0.014 & 0.014 \\
\hline \multicolumn{7}{|c|}{ Panel B: $R_{t}=\alpha+\sum_{i=1}^{3} \beta_{i} R_{t-i}+\sum_{j=-2}^{2} \gamma_{j} S S I_{t-j}+\sum_{k=1}^{32} \theta_{k} S S M_{k t}+\varepsilon_{t}$} \\
\hline \multirow[t]{2}{*}{$\alpha$} & 0.088 & 0.080 & $0.082^{*}$ & 0.079 & $0.080^{*}$ & $0.079^{*}$ \\
\hline & {$[1.50]$} & {$[1.53]$} & {$[1.65]$} & {$[1.62]$} & {$[1.72]$} & {$[1.79]$} \\
\hline \multirow[t]{2}{*}{$R_{t-1}$} & $-.108^{* * *}$ & $-.078^{* * *}$ & $-.080^{* * * *}$ & $-.073^{* * *}$ & $-.068^{* * *}$ & $-.064^{* * * *}$ \\
\hline & {$[-5.24]$} & {$[-3.77]$} & {$[-3.91]$} & {$[-3.59]$} & {$[-3.24]$} & {$[-3.08]$} \\
\hline \multirow[t]{2}{*}{$R_{t-2}$} & $-.067^{* * * *}$ & -0.013 & -0.013 & -0.018 & -0.006 & 0.003 \\
\hline & {$[-3.19]$} & {$[-0.59]$} & {$[-0.62]$} & {$[-0.84]$} & {$[-0.26]$} & {$[0.16]_{* *}$} \\
\hline \multirow[t]{2}{*}{$R_{t-3}$} & $0.047^{* * *}$ & $0.040^{*}$ & $0.047^{* *}$ & 0.03 & $0.046^{* *}$ & $0.049^{* *}$ \\
\hline & {$[2.43]$} & [1.94] & [2.29] & [1.59] & {$[2.22]$} & {$[2.37]$} \\
\hline \multirow[t]{2}{*}{$S S I_{t-2}$} & -0.055 & -0.017 & -0.033 & -0.055 & -0.003 & -0.027 \\
\hline & {$[-0.42]$} & {$[-0.15]$} & {$[-0.31]$} & {$[-0.53]$} & {$[-0.03]$} & {$[-0.28]$} \\
\hline \multirow[t]{2}{*}{$S S I_{t-1}$} & -0.07 & -0.03 & -0.038 & -0.004 & 0.031 & 0.046 \\
\hline & {$[-0.56]$} & {$[-0.26]$} & {$[-0.35]$} & {$[-0.04]$} & {$[0.30]_{* * *}$} & {$[0.47]_{* * *}$} \\
\hline \multirow[t]{2}{*}{$S S I_{t}$} & $-.535^{* * *}$ & $-.517^{* * *}$ & $-.475^{* * *}$ & $-.413^{* * *}$ & $-.384^{* * *}$ & $-.383^{* * *}$ \\
\hline & {$[-4.33]$} & {$[-4.73]$} & {$[-4.49]$} & {$[-3.99]$} & {$[-3.91]$} & {$[-4.03]$} \\
\hline \multirow[t]{2}{*}{$S S I_{t+1}$} & $-.236^{*}$ & $-.253^{* *}$ & $-.267^{* * *}$ & $-.268^{* * * *}$ & $-.236^{* * \vec{*}}$ & $-.221^{* * *}$ \\
\hline & {$[-1.95]_{* * *}$} & {$[-2.33]$} & {$[-2.64]_{* * *}$} & {$[-2.68]_{* * *}$} & {$[-2.48]$} & {$[-2.40]$} \\
\hline \multirow[t]{2}{*}{$S S I_{t+2}$} & $0.307^{* * *}$ & $0.259^{* * *}$ & $0.258^{* * *}$ & $0.248^{* * * *}$ & $0.230^{* * *}$ & $0.215^{* *}$ \\
\hline & [2.63] & {$[2.52]$} & [2.66] & [2.59] & [2.49] & {$[2.42]$} \\
\hline Adj- $R^{2}$ & 0.046 & 0.045 & 0.051 & 0.042 & 0.053 & 0.048 \\
\hline
\end{tabular}


Table 13: Call Option Regressions

This table presents the results of the regression model: $R_{t}=\alpha+\sum_{i=1}^{3} \beta_{i} R_{t-i}+\gamma_{0} S S I_{t}+\varepsilon_{t}$. The regressions are run on call options grouped by expiration and moneyness. Here, $R_{t}$ refers to the daily return of a call option, $R_{t-i}$ is the $\mathrm{i}^{\text {th }}$ lagged daily return of the same call option, and $S S I_{t}=\left(A_{t}-E_{t}\right) / \sigma$ refers to the standardized surprise of crude oil inventory on day $\mathrm{t}$ (zero if there is no inventory news on day $\mathrm{t}$ ).

\begin{tabular}{|c|c|c|c|c|c|c|c|c|c|c|}
\hline & \multicolumn{10}{|c|}{ Expiration } \\
\hline & \multicolumn{5}{|c|}{1} & \multicolumn{5}{|c|}{2} \\
\hline & DITM & ITM & NTM & OTM & DOTM & DITM & ITM & NTM & OTM & DOTM \\
\hline \multirow[t]{2}{*}{$\alpha$} & $1.060^{* * * *}$ & $1.442^{* * * *}$ & $-1.73^{* * *}$ & $-11.1^{* * *}$ & $-17.7^{* * *}$ & $0.870^{* * *}$ & $0.635^{* * * *}$ & $-.594^{* * * 4}$ & $-2.71^{* * *}$ & $-7.64^{* * *}$ \\
\hline & [19.13] & {$[7.82]$} & {$[-6.07]$} & {$[-33.3]$} & {$[-48.6]$} & [19.25] & {$[5.40]$} & {$[-3.82]$} & {$[-15.5]$} & {$[-63.6]$} \\
\hline \multirow{2}{*}{$R_{t-1}$} & $-.034^{* * *}$ & $-.045^{* * *}$ & $-.057^{* * * *}$ & $-.091^{* \overrightarrow{* * *}}$ & $-.043^{* * * *}$ & $-.016^{* * *}$ & $-.038^{* * *}$ & $-.034^{* \text { *** }}$ & $-.015^{* *}$ & $-.021^{* * * *}$ \\
\hline & {$[-8.04]$} & {$[-6.01]$} & {$[-6.99]$} & {$[-11.40]$} & {$[-5.57]$} & {$[-4.45]$} & {$[-5.49]$} & {$[-4.60]$} & {$[-2.11]$} & {$[-4.86]$} \\
\hline \multirow{2}{*}{$R_{t-2}$} & $0.023^{* * *}$ & -0.007 & $-.040^{* * * *}$ & $-.050^{* * *}$ & 0.012 & -0.001 & $-.024^{* * *}$ & $-.027^{* * * *}$ & $-.023^{* * *}$ & $0.019^{* * *}$ \\
\hline & {$[5.57]_{* * *}$} & {$[-0.91]_{* * *}$} & {$[-4.74]$} & {$[-6.03]$} & {$[1.45]$} & {$[-0.27]$} & {$[-3.47]$} & {$[-3.64]$} & {$[-3.29]$} & {$[4.36]$} \\
\hline \multirow[t]{2}{*}{$R_{t-3}$} & $-.037^{* * *}$ & $-.052^{* * *}$ & $-.078^{* * * *}$ & $-.091^{* \vec{*} *}$ & $0.018^{* *}$ & -0.003 & $-.034^{* * *}$ & $-.029^{* * *}$ & $-.027^{* * *}$ & $0.039^{* * *}$ \\
\hline & {$[-8.78]$} & {$[-6.95]_{* * *}$} & {$[-9.22]$} & {$[-10.40]$} & {$[2.05]_{* * *}$} & {$[-0.91]$} & {$[-4.84]$} & {$[-3.96]$} & {$[-3.83]$} & {$[10.08]$} \\
\hline \multirow[t]{2}{*}{$S S I_{t}$} & $-2.480^{* * *}$ & $-4.410^{* * *}$ & $-6.060^{* * *}$ & $-6.740^{* * *}$ & $-4.670^{* * *}$ & $-2.140^{* * *}$ & $-3.440^{* * *}$ & $-4.350^{* * *}$ & $-4.970^{* * *}$ & $-4.480^{* * *}$ \\
\hline & {$[-23.0]$} & {$[-11.6]$} & {$[-10.1]$} & {$[-10.0]$} & {$[-7.84]$} & {$[-21.1]$} & {$[-12.9]$} & {$[-12.3]$} & {$[-12.6]$} & {$[-17.5]$} \\
\hline \multirow[t]{4}{*}{$\operatorname{Adj}-R^{2}$} & 0.017 & 0.013 & 0.018 & 0.023 & 0.005 & 0.009 & 0.011 & 0.011 & 0.009 & 0.008 \\
\hline & \multicolumn{10}{|c|}{ Expiration } \\
\hline & \multicolumn{5}{|c|}{3} & \multicolumn{5}{|c|}{4} \\
\hline & DITM & ITM & NTM & OTM & DOTM & DITM & ITM & NTM & OTM & DOTM \\
\hline \multirow[t]{2}{*}{$\alpha$} & $0.839^{* * * *}$ & $0.976^{* * * *}$ & -0.043 & $-.977^{* * *}$ & $-3.190^{* * *}$ & $0.601^{* * *}$ & $0.769^{* * *}$ & $0.198^{* * * *}$ & $-.385^{* * * *}$ & $-1.030^{* * * *}$ \\
\hline & [40.52] & [21.62] & {$[-0.81]$} & {$[-15.8]$} & {$[-80.9]$} & [46.37] & [29.57] & {$[6.85]$} & {$[-11.5]$} & {$[-49.2]$} \\
\hline \multirow[t]{2}{*}{$R_{t-1}$} & $-.028^{* * *}$ & $-.037^{* * *}$ & $-.035^{* \vec{*} *}$ & $-.010^{* * *}$ & $0.008^{* * *}$ & $-.030^{* * *}$ & $-.041^{* * *}$ & $-.056^{* * *}$ & $-.045^{* * *}$ & $-.065^{* * * *}$ \\
\hline & {$[-12.2]$} & {$[-9.87]$} & {$[-8.78]$} & {$[-2.60]$} & {$[3.90]$} & {$[-13.6]$} & {$[-12.2]$} & {$[-16.2]$} & {$[-12.5]$} & {$[-38.6]$} \\
\hline \multirow[t]{2}{*}{$R_{t-2}$} & -0.001 & -0.004 & 0.001 & $0.016^{* * *}$ & $0.053^{* * *}$ & $0.028^{* * *}$ & $0.020^{* * *}$ & $0.016^{* * *}$ & $0.055^{* * *}$ & $0.089^{* * *}$ \\
\hline & {$[-0.43]$} & {$[-0.97]$} & {$[0.30]$} & [4.15] & [24.95] & {$[12.97]$} & {$[5.98]$} & {$[4.67]$} & [14.91] & {$[52.35]$} \\
\hline \multirow[t]{2}{*}{$R_{t-3}$} & $-.014^{* * *}$ & $-.008^{* *}$ & $-.008^{* *}$ & $0.008^{*}$ & $0.055^{* * *}$ & $0.023^{* * *}$ & $0.020^{* * *}$ & $0.011^{* * *}$ & $0.042^{* * *}$ & $0.051^{* * *}$ \\
\hline & {$[-5.91]$} & {$[-2.08]_{* * *}$} & {$[-2.12]$} & {$[1.91]_{* * *}$} & {$[26.61]$} & [11.39] & {$[6.18]_{* * *}$} & {$[3.36]_{* * *}$} & {$[11.80]$} & {$[37.10]$} \\
\hline \multirow[t]{2}{*}{$S S I_{t}$} & $-1.410^{* * *}$ & $-2.230^{* * *}$ & $-2.420^{* * *}$ & $-2.900^{* * *}$ & $-2.780^{* * *}$ & $-.909^{* * *}$ & $-1.320^{* * *}$ & $-1.200^{* * *}$ & $-1.260^{* * *}$ & $-1.200^{* * *}$ \\
\hline & {$[-31.5]$} & {$[-22.6]$} & {$[-20.5]$} & {$[-21.2]$} & {$[-31.4]$} & {$[-33.3]$} & {$[-23.0]$} & {$[-18.8]$} & {$[-17.3]$} & {$[-26.8]$} \\
\hline $\operatorname{Adj}-R^{2}$ & 0.007 & 0.008 & 0.007 & 0.007 & 0.010 & 0.007 & 0.008 & 0.007 & 0.010 & 0.017 \\
\hline
\end{tabular}




\section{Table 14: Put Option Regressions}

This table presents the results of the regression model: $R_{t}=\alpha+\sum_{i=1}^{3} \beta_{i} R_{t-i}+\gamma_{0} S S I_{t}+\varepsilon_{t}$. The regressions are run on put options grouped by expiration and moneyness. Here, $R_{t}$ refers to the daily return of a put option, $S S I_{t}=\left(A_{t}-E_{t}\right) / \sigma$ refers to the standardized surprise of crude oil inventory on day $\mathrm{t}$ (zero if there is no inventory news on day $\mathrm{t}$ ), and $R_{t-i}$ is the $i^{\text {th }}$ lagged daily return of the same put option.

\begin{tabular}{|c|c|c|c|c|c|c|c|c|c|c|}
\hline & \multicolumn{10}{|c|}{ Expiration } \\
\hline & \multicolumn{5}{|c|}{1} & \multicolumn{5}{|c|}{2} \\
\hline & DITM & ITM & NTM & OTM & DOTM & DITM & ITM & NTM & OTM & DOTM \\
\hline \multirow[t]{2}{*}{$\alpha$} & $0.536^{* * *}$ & $0.970^{* * * *}$ & $-4.560^{* * *}$ & $-14.10^{* * *}$ & $-17.30^{* * * 2}$ & $0.954^{* * * *}$ & $0.946^{* * *}$ & $-1.29^{* * * *}$ & $-3.68^{* * *}$ & $-7.83^{* * * *}$ \\
\hline & {$[9.30]$} & {$[5.08]$} & {$[-15.5]$} & {$[-37.5]$} & {$[-45.6]$} & {$[24.00]$} & {$[7.49]$} & {$[-8.28]$} & {$[-19.9]$} & {$[-54.1]$} \\
\hline \multirow{2}{*}{$R_{t-1}$} & $-.060^{* * *}$ & $-.024^{* * *}$ & $-.048^{* *_{*}^{* *}}$ & $-.055^{* \text { *** }}$ & $-.097^{* *_{*}^{* *}}$ & $-.056^{* * * *}$ & $-.047^{* * *}$ & $-.060^{* *_{*}^{* *}}$ & $-.051^{* \text { *** }}$ & $-.086^{* * * *}$ \\
\hline & {$[-10.8]$} & {$[-2.79]$} & {$[-5.37]$} & {$[-6.20]$} & {$[-11.9]$} & {$[-12.0]$} & {$[-6.03]$} & {$[-7.43]$} & {$[-6.44]$} & {$[-17.4]$} \\
\hline \multirow{2}{*}{$R_{t-2}$} & $-.015^{* \text { *** }}$ & $-.016^{*}$ & $-.038^{* \vec{*} *}$ & $-.037^{* \text { *** }}$ & $-.081^{* * *}$ & $0.024^{* * *}$ & 0.001 & $-.025^{* * * *}$ & $-.021^{* * * *}$ & $-.041^{* * * *}$ \\
\hline & {$[-2.78]$} & {$[-1.83]$} & {$[-4.06]$} & {$[-3.92]$} & {$[-9.17]$} & {$[5.25]$} & {$[0.14]$} & {$[-3.11]$} & {$[-2.61]$} & {$[-8.12]$} \\
\hline \multirow{2}{*}{$R_{t-3}$} & $0.017^{* * *}$ & $-.057^{* * * *}$ & $-.087^{* * *}$ & $-.080^{* * * *}$ & $-.111^{* * *}$ & $0.080^{* * *}$ & 0.005 & $-.036^{* * * *}$ & $-.039^{* 3 *}$ & $-.055^{* * *}$ \\
\hline & {$[3.21]$} & {$[-6.53]$} & {$[-9.12]$} & {$[-8.44]$} & {$[-12.4]$} & [18.91] & {$[0.61]$} & {$[-4.46]$} & {$[-4.89]$} & {$[-11.0]$} \\
\hline \multirow[t]{2}{*}{$S S I_{t}$} & $1.161^{* * *}$ & $3.617^{* * *}$ & $5.450^{* * *}$ & $7.514^{* * *}$ & $7.075^{* * *}$ & $1.109^{* * *}$ & $2.443^{* * *}$ & $3.351^{* * *}$ & $4.226^{* * * *}$ & $3.313^{* * *}$ \\
\hline & [11.06] & [9.51] & [9.36] & [10.94] & {$[12.75]$} & [10.49] & {$[8.60]$} & [9.63] & [11.05] & [11.74] \\
\hline \multirow[t]{4}{*}{$\operatorname{Adj}-R^{2}$} & 0.007 & 0.010 & 0.015 & 0.017 & 0.036 & 0.014 & 0.006 & 0.009 & 0.010 & 0.013 \\
\hline & \multicolumn{10}{|c|}{ Expiration } \\
\hline & \multicolumn{5}{|c|}{3} & \multicolumn{5}{|c|}{4} \\
\hline & DITM & ITM & NTM & OTM & DOTM & DITM & ITM & NTM & OTM & DOTM \\
\hline \multirow[t]{2}{*}{$\alpha$} & $0.803^{* * * *}$ & $1.104^{* * * *}$ & $-.351^{* * * *}$ & $-1.74^{* * * *}$ & $-3.030^{* * * 2}$ & $0.244^{* * * *}$ & $0.488^{* * * *}$ & $-.130^{* * * *}$ & $-.938^{* * * *}$ & $-1.010^{* * *}$ \\
\hline & [38.61] & {$[22.05]$} & {$[-6.86]$} & {$[-30.6]$} & {$[-78.4]$} & [21.89] & {$[17.24]$} & {$[-5.01]$} & {$[-34.9]$} & {$[-61.5]$} \\
\hline \multirow[t]{2}{*}{$R_{t-1}$} & $-.054^{* * *}$ & $-.033^{* * * *}$ & $-.050^{* \vec{*} *}$ & $-.044^{* \vec{*} *}$ & $-.030^{* * * *}$ & $-.058^{* * *}$ & $-.088^{* * *}$ & $-.105^{\text {**** }}$ & $-.184^{* * * *}$ & $-.084^{* * *}$ \\
\hline & {$[-19.1]$} & {$[-7.24]$} & {$[-12.0]$} & {$[-10.8]$} & {$[-13.8]$} & {$[-25.8]$} & {$[-22.2]$} & {$[-29.5]$} & {$[-54.3]$} & {$[-50.7]$} \\
\hline \multirow[t]{2}{*}{$R_{t-2}$} & $0.013^{* * *}$ & $0.020^{* * * *}$ & -0.004 & $0.011^{* *}$ & 0.000 & $0.032^{* * *}$ & $0.019^{* * * *}$ & 0.002 & $0.008^{* * *}$ & $0.027^{* * * *}$ \\
\hline & {$[4.49]$} & {$[4.32]$} & {$[-0.94]$} & {$[2.57]$} & {$[-0.04]$} & {$[13.56]$} & {$[4.51]$} & {$[0.53]$} & {$[2.11]$} & {$[15.60]$} \\
\hline \multirow[t]{2}{*}{$R_{t-3}$} & $0.060^{* * *}$ & $-.040^{* * *}$ & $-.039^{* * * *}$ & $-.031^{* * *}$ & $-.044^{* * * *}$ & $0.031^{* *}$ & -0.003 & $-.026^{* * *}$ & $-.024^{* * *}$ & $-.014^{* * *}$ \\
\hline & [21.78] & {$[-9.31]$} & {$[-8.89]$} & {$[-7.44]$} & {$[-19.9]$} & {$[13.79]$} & {$[-0.68]$} & {$[-7.12]$} & {$[-6.50]$} & {$[-8.25]$} \\
\hline \multirow[t]{2}{*}{$S S I_{t}$} & $0.743^{* * *}$ & $1.301^{* * *}$ & $1.566^{* * *}$ & $2.032^{* * *}$ & $1.713^{* * *}$ & $0.227^{* * *}$ & $0.466^{* * *}$ & $0.716^{* * *}$ & $0.899^{* * *}$ & $0.994^{* * *}$ \\
\hline & {$[15.35]$} & [11.63] & [13.79] & {$[17.05]$} & [21.94] & [9.34] & {$[7.72]$} & {$[12.73]$} & {$[15.48]$} & [29.35] \\
\hline $\operatorname{Adj}-R^{2}$ & 0.009 & 0.006 & 0.006 & 0.007 & 0.004 & 0.006 & 0.009 & 0.013 & 0.035 & 0.010 \\
\hline
\end{tabular}




\section{Table 15: Call Option Market Regression with Lag and Lead Inventory Surprises}

This table reports the results of the regression model: $R_{t}=\alpha+\sum_{i=1}^{3} \beta_{i} R_{t-i}+\sum_{j=-2}^{2} \gamma_{j} S S I_{t-j}+\sum_{k=1}^{32} \theta_{k} S S M_{k t}+\varepsilon_{t}$, for the call option contracts. In the regressions, $R_{t}$ refers to the daily return of crude oil futures, $R_{t-i}$ is the $\mathrm{i}^{\text {th }}$ lagged daily return of crude oil futures, $S S I_{t-j}$ is the lag/lead standardized surprise that allows us to investigate news anticipation effects, and $S S M_{k t}$ refers to the standardized surprise of the $k^{t h}$ news variable on day $t$. Due to the limit of space, we do not report the parameters for $S S M_{k t}$.

\begin{tabular}{|c|c|c|c|c|c|c|c|c|c|c|}
\hline & \multicolumn{10}{|c|}{ Expiration } \\
\hline & \multicolumn{5}{|c|}{1} & \multicolumn{5}{|c|}{2} \\
\hline & DITM & ITM & NTM & OTM & DOTM & DITM & ITM & NTM & OTM & DOTM \\
\hline \multirow[t]{2}{*}{$\alpha$} & $1.409^{* * * *}$ & $2.011^{* * * *}$ & $-.891^{* * * *}$ & $-9.83^{* * * *}$ & $-16.2^{* * *}$ & $1.175^{* * *}$ & $1.071^{* * * *}$ & -0.015 & $-1.92^{* * *}$ & $-6.65^{* * * *}$ \\
\hline & [24.96] & [10.79] & {$[-3.04]$} & {$[-27.4]$} & {$[-44.4]$} & {$[25.65]$} & [8.91] & {$[-0.10]$} & {$[-10.7]$} & {$[-51.7]$} \\
\hline \multirow[t]{2}{*}{$R_{t-1}$} & $-.041^{* * *}$ & $-.043^{* * *}$ & $-.055^{* \overrightarrow{* * *}}$ & $-.054^{* * * *}$ & $-.091^{* * * *}$ & $-.050^{* * *}$ & $-.035^{* * *}$ & $-.028^{* \vec{*} *}$ & $-.016^{* \vec{*}}$ & $-.023^{* * * *}$ \\
\hline & {$[-8.63]$} & {$[-5.42]$} & {$[-6.42]$} & {$[-6.40]$} & {$[-11.3]$} & {$[-11.2]$} & {$[-4.89]$} & {$[-3.72]$} & {$[-2.24]$} & {$[-5.23]$} \\
\hline \multirow{2}{*}{$R_{t-2}$} & $-.012^{* \bar{k}}$ & $-.037^{* * *}$ & $-.050^{* \vec{*} *}$ & $-.057^{* * * *}$ & $-.025^{* * * *}$ & $-.015^{* * *}$ & $-.023^{* * * *}$ & $-.028^{* * * *}$ & $-.023^{* * * *}$ & $0.008^{*}$ \\
\hline & {$[-2.53]$} & {$[-4.58]$} & {$[-5.64]$} & {$[-6.54]$} & {$[-3.05]$} & {$[-3.23]$} & {$[-3.16]$} & {$[-3.65]$} & {$[-3.19]$} & {$[1.70]$} \\
\hline \multirow{2}{*}{$R_{t-3}$} & $-.058^{* * *}$ & $-.058^{* *^{*} *}$ & $-.077^{* \vec{*} *}$ & $-.089^{* * *}$ & $-.019^{* *}$ & $-.045^{* * *}$ & $-.043^{* * * *}$ & $-.043^{* \vec{*} *}$ & $-.034^{* * * *}$ & $0.010^{* *}$ \\
\hline & {$[-12.4]$} & {$[-7.26]$} & {$[-8.64]$} & {$[-9.91]$} & {$[-2.17]$} & {$[-10.4]$} & {$[-6.05]$} & {$[-5.73]$} & {$[-4.80]$} & [2.39] \\
\hline \multirow[t]{2}{*}{$S S I_{t-2}$} & $-1.66^{* * *}$ & $-2.21^{* * * *}$ & $-2.84^{* * * *}$ & $-3.85^{\text {**** }}$ & $-7.47^{\text {**** }}$ & $-.720^{* * *}$ & -0.348 & -0.494 & -0.125 & $-1.97^{* * *}$ \\
\hline & {$[-13.7]_{* *}$} & {$[-5.28]_{* *}$} & {$[-4.29]$} & {$[-5.05]$} & {$[-11.0]$} & {$[-7.01]_{* * *}$} & {$[-1.32]$} & {$[-1.40]$} & {$[-0.31]$} & {$[-7.26]$} \\
\hline \multirow[t]{2}{*}{$S S I_{t-1}$} & $-.470^{* * * *}$ & $-1.70^{* * * *}$ & $-2.38^{* * * *}$ & $-2.49^{* \text { *** }}$ & -0.546 & $-.306^{* * * *}$ & -0.384 & -0.198 & 0.141 & 0.358 \\
\hline & {$[-4.14]$} & {$[-4.36]$} & {$[-3.86]$} & {$[-3.46]$} & {$[-0.81]$} & {$[-3.09]$} & {$[-1.46]$} & {$[-0.56]$} & {$[0.35]$} & {$[1.26]$} \\
\hline \multirow[t]{2}{*}{$S S I_{t}$} & $-1.99^{* * * *}$ & $-4.13^{* * * *}$ & $-5.89^{* \vec{*} *}$ & $-6.34^{* * * *}$ & $-6.18^{* * * *}$ & $-1.82^{* \vec{*} *}$ & $-3.46^{* * * *}$ & $-4.52^{* * * *}$ & $-5.19^{* * *}$ & $-5.12^{* * *}$ \\
\hline & {$[-17.5]$} & {$[-10.9]$} & {$[-9.88]$} & {$[-9.11]$} & {$[-9.86]$} & {$[-18.1]$} & {$[-13.0]$} & {$[-12.8]$} & {$[-13.1]$} & {$[-19.1]$} \\
\hline \multirow[t]{2}{*}{$S S I_{t+1}$} & $-.820^{* * * *}$ & $-1.87^{* * *}$ & $-2.08^{* * * *}$ & $-2.26^{* * *}$ & $-3.98^{* * * *}$ & $-1.16^{* * * *}$ & $-2.08^{* * * *}$ & $-2.52^{* * * *}$ & $-3.03^{* * *}$ & $-3.57^{* \vec{*} *}$ \\
\hline & {$[-7.13]$} & {$[-4.76]$} & {$[-3.40]$} & {$[-3.19]$} & {$[-6.15]$} & {$[-12.7]$} & {$[-8.41]$} & {$[-7.63]$} & {$[-8.23]$} & {$[-14.3]$} \\
\hline \multirow[t]{2}{*}{$S S I_{t+2}$} & $1.541^{* * *}$ & $3.710^{* * *}$ & $5.886^{* * *}$ & $7.368^{* * *}$ & $6.739^{* * * *}$ & $0.753^{* * *}$ & $2.004^{* * *}$ & $2.648^{* * *}$ & $3.196^{* * *}$ & $2.694^{* * *}$ \\
\hline & [13.55] & [9.39] & [9.54] & [10.21] & {$[10.50]$} & {$[8.56]$} & [8.52] & [8.47] & [9.12] & [11.28] \\
\hline $\operatorname{Adj}-R^{2}$ & 0.076 & 0.065 & 0.065 & 0.065 & 0.087 & 0.057 & 0.052 & 0.05 & 0.046 & 0.062 \\
\hline
\end{tabular}




\section{Table 15 (contd.): Call Option Market Regression with Lag and Lead Inventory Surprises}

This table reports the results of the regression model: $R_{t}=\alpha+\sum_{i=1}^{3} \beta_{i} R_{t-i}+\sum_{j=-2}^{2} \gamma_{j} S S I_{t-j}+\sum_{k=1}^{32} \theta_{k} S S M_{k t}+\varepsilon_{t}$, for the call option contracts. In the regressions, $R_{t}$ refers to the daily return of crude oil futures, $R_{t-i}$ is the $\mathrm{i}^{\text {th }}$ lagged daily return of crude oil futures, $S S I_{t-j}$ is the lag/lead standardized surprise that allows us to investigate news anticipation effects, and $S S M_{k t}$ refers to the standardized surprise of the $k^{t h}$ news variable on day $t$. Due to space limitations, we do not report the parameters for $S S M_{k t}$.

\begin{tabular}{|c|c|c|c|c|c|c|c|c|c|c|}
\hline & \multicolumn{10}{|c|}{ Expiration } \\
\hline & \multicolumn{5}{|c|}{3} & \multicolumn{5}{|c|}{4} \\
\hline & DITM & ITM & NTM & OTM & DOTM & DITM & ITM & NTM & OTM & DOTM \\
\hline \multirow[t]{2}{*}{$\alpha$} & $0.929^{* * * *}$ & $1.141^{* * * *}$ & $0.264^{* * * *}$ & $-.529^{* * * *}$ & $-2.68^{* * * *}$ & $0.637^{* * * *}$ & $0.840^{* * * *}$ & $0.295^{* * * *}$ & $-.115^{* * *}$ & $-.659^{* * * *}$ \\
\hline & [43.89] & {$[25.16]$} & [4.90] & {$[-8.43]$} & {$[-64.6]$} & [48.94] & [32.09] & [10.13] & {$[-3.42]$} & {$[-30.3]$} \\
\hline \multirow[t]{2}{*}{$R_{t-1}$} & $-.035^{* * *}$ & $-.032^{* * *}$ & $-.035^{* * *}$ & $-.010^{* *}$ & $0.018^{* * * *}$ & $-.025^{* * * *}$ & $-.035^{* * *}$ & $-.058^{* * * *}$ & $-.043^{* * *}$ & $-.015^{* * *}$ \\
\hline & {$[-13.6]$} & {$[-8.26]$} & {$[-8.84]$} & {$[-2.45]$} & [8.49] & {$[-11.5]$} & {$[-10.5]$} & {$[-16.8]$} & {$[-11.8]$} & {$[-8.55]$} \\
\hline \multirow[t]{2}{*}{$R_{t-2}$} & $-.008^{* * *}$ & -0.001 & $-.008^{*}$ & 0.006 & $0.037^{* * *}$ & $0.021^{* * * *}$ & $0.019^{* * * *}$ & $0.009^{* *}$ & $0.039^{* * *}$ & $0.069^{* * *}$ \\
\hline & {$[-3.18]$} & {$[-0.17]$} & {$[-1.94]$} & [1.47] & {$[16.75]$} & {$[9.58]$} & {$[5.58]$} & {$[2.48]$} & [10.38] & [38.75] \\
\hline \multirow[t]{2}{*}{$R_{t-3}$} & $-.033^{* * *}$ & $-.028^{* * * *}$ & $-.025^{* * *}$ & -0.003 & $0.022^{* * *}$ & $-.006^{* * *}$ & -0.003 & -0.005 & $0.023^{* * * *}$ & $0.027^{* * *}$ \\
\hline & {$[-13.0]$} & {$[-7.34]$} & {$[-6.11]$} & {$[-0.82]$} & {$[9.87]$} & {$[-2.91]$} & {$[-0.85]$} & {$[-1.41]$} & [6.28] & [14.94] \\
\hline \multirow[t]{2}{*}{$S S I_{t-2}$} & $-.615^{* * *}$ & $-.200^{* *}$ & -0.068 & -0.22 & $-1.19^{* * *}$ & $-.262^{* * * *}$ & 0.019 & 0.055 & 0.012 & $-.518^{* * * *}$ \\
\hline & {$[-13.4]$} & {$[-2.03]$} & {$[-0.57]$} & {$[-1.59]$} & {$[-13.6]$} & {$[-9.17]$} & {$[0.34]$} & {$[0.86]$} & {$[0.17]$} & {$[-11.2]$} \\
\hline \multirow[t]{2}{*}{$S S I_{t-1}$} & $-.382^{* * *}$ & $-.377^{* * *}$ & $-.459^{* * * *}$ & $-.267^{*}$ & $-.173^{*}$ & $0.099^{* * * *}$ & $0.259^{* * *}$ & 0.062 & $0.260^{* * *}$ & $0.467^{* * *}$ \\
\hline & {$[-8.83]$} & {$[-3.87]$} & {$[-3.99]$} & {$[-1.95]$} & {$[-1.94]$} & [3.59] & {$[4.56]$} & {$[0.98]$} & {$[3.57]$} & {$[9.84]$} \\
\hline \multirow[t]{2}{*}{$S S I_{t}$} & $-1.28^{* * *}$ & $-2.10^{* * * *}$ & $-2.28^{* * * *}$ & $-2.77^{* * * *}$ & $-3.09^{* * * *}$ & $-.874^{* * * *}$ & $-1.29^{* * *}$ & $-1.27^{* * *}$ & $-1.30^{* * *}$ & $-1.34^{* * *}$ \\
\hline & {$[-28.6]$} & {$[-21.3]$} & {$[-19.6]$} & {$[-20.3]$} & {$[-35.4]$} & {$[-31.7]$} & {$[-22.6]$} & {$[-20.2]$} & {$[-18.1]$} & {$[-29.2]$} \\
\hline \multirow[t]{2}{*}{$S S I_{t+1}$} & $-.630^{* * * *}$ & $-1.11^{* * *}$ & $-1.38^{* * * *}$ & $-1.56^{* * *}$ & $-2.34^{* * * *}$ & $-.519^{* * *}$ & $-.824^{* * *}$ & $-.819^{* * * *}$ & $-1.02^{* * * *}$ & $-1.24^{* * * *}$ \\
\hline & {$[-14.3]$} & {$[-11.5]$} & {$[-12.0]$} & {$[-11.6]$} & {$[-27.5]$} & {$[-19.0]$} & {$[-14.7]$} & {$[-13.1]$} & {$[-14.4]$} & {$[-27.4]$} \\
\hline \multirow[t]{2}{*}{$S S I_{t+2}$} & $0.950^{* * * *}$ & $1.413^{* * * *}$ & $1.562^{* * *}$ & $1.864^{* * * *}$ & $1.907^{* * *}$ & $0.401^{* * * *}$ & $0.803^{* * * *}$ & $0.928^{* * * *}$ & $0.872^{* * * *}$ & $1.155^{* * *}$ \\
\hline & {$[22.42]$} & [14.89] & {$[13.81]$} & [14.03] & [22.47] & {$[15.07]$} & [14.60] & [14.80] & [12.38] & {$[25.72]$} \\
\hline $\operatorname{Adj}-R^{2}$ & 0.060 & 0.046 & 0.042 & 0.044 & 0.060 & 0.048 & 0.040 & 0.040 & 0.047 & 0.060 \\
\hline
\end{tabular}




\section{Table 16: Put Options Market Regression with Lag and Lead Inventory Surprises}

This table reports the results of the regression model: $R_{t}=\alpha+\sum_{i=1}^{3} \beta_{i} R_{t-i}+\sum_{j=-2}^{2} \gamma_{j} S S I_{t-j}+\sum_{k=1}^{32} \theta_{k} S S M_{k t}+\varepsilon_{t}$, for the put option contracts. In the regressions, $R_{t}$ refers to the daily return of crude oil futures, $R_{t-i}$ is the $\mathrm{i}^{\text {th }}$ lagged daily return of crude oil futures, $S S I_{t-j}$ is the lag/lead standardized surprise that allows us to investigate news anticipation effects, and $S S M_{k t}$ refers to the standardized surprise of the $k^{t h}$ news variable on day $t$. Due to space limitations, we do not report the parameters for $S S M_{k t}$.

\begin{tabular}{|c|c|c|c|c|c|c|c|c|c|c|}
\hline & \multicolumn{10}{|c|}{ Expiration } \\
\hline & \multicolumn{5}{|c|}{1} & \multicolumn{5}{|c|}{2} \\
\hline & DITM & ITM & NTM & OTM & DOTM & DITM & ITM & NTM & OTM & DOTM \\
\hline \multirow[t]{2}{*}{$\alpha$} & $1.092^{* * * *}$ & $0.924^{* * * *}$ & $-4.33^{* * * *}$ & $-13.5^{\text {*** }}$ & $-17.8^{* * *}$ & $0.879^{* * * *}$ & $0.821^{* * * 4}$ & $-1.24^{* * *}$ & $-3.63^{* * *}$ & $-8.29^{* * * *}$ \\
\hline & [17.14] & [4.65] & {$[-14.9]$} & {$[-36.4]$} & {$[-49.0]$} & [19.04] & [6.28] & {$[-7.93]$} & {$[-20.1]$} & {$[-59.1]$} \\
\hline \multirow[t]{2}{*}{$R_{t-1}$} & -0.007 & 0.008 & $-.031^{* * * *}$ & $-.058^{* * *}$ & $-.116^{* * *}$ & $-.013^{* * * *}$ & -0.01 & $-.027^{* * * *}$ & $-.019^{* *}$ & $-.080^{* * * *}$ \\
\hline & {$[-1.28]$} & {$[1.00]$} & {$[-3.52]$} & {$[-6.48]$} & {$[-13.7]$} & {$[-2.72]$} & {$[-1.23]$} & {$[-3.48]$} & {$[-2.53]$} & {$[-16.5]$} \\
\hline \multirow[t]{2}{*}{$R_{t-2}$} & 0 & 0.008 & $-.046^{* * * *}$ & $-.050^{* * * *}$ & $-.108^{* * *}$ & $-.012^{* \vec{*}}$ & $-.020^{* \vec{*}}$ & $-.026^{* \text { *ै* }}$ & $-.021^{* * * *}$ & $-.058^{* * *}$ \\
\hline & {$[-0.01]$} & {$[0.90]$} & {$[-5.03]$} & {$[-5.33]$} & {$[-12.3]$} & {$[-2.50]$} & {$[-2.52]$} & {$[-3.29]$} & {$[-2.71]$} & {$[-11.7]$} \\
\hline \multirow{2}{*}{$R_{t-3}$} & $0.047^{* * *}$ & -0.006 & $-.054^{* * * *}$ & $-.066^{* * *}$ & $-.103^{* * *}$ & $0.064^{* * *}$ & 0.009 & $-.033^{* * * *}$ & $-.041^{* * * *}$ & $-.077^{* * *}$ \\
\hline & {$[9.44]$} & {$[-0.73]$} & {$[-6.00]$} & {$[-7.03]$} & {$[-11.7]$} & {$[14.25]$} & [1.18] & {$[-4.19]$} & {$[-5.42]$} & {$[-16.0]$} \\
\hline \multirow[t]{2}{*}{$S S I_{t-2}$} & $0.859^{* * *}$ & 0.503 & $1.492^{* *}$ & $2.657^{* * *}$ & $4.594^{* * *}$ & $1.406^{* * *}$ & -0.05 & -0.134 & 0.122 & $0.625^{* *}$ \\
\hline & [5.99] & {$[1.11]$} & {$[2.31]$} & {$[3.50]$} & {$[7.22]$} & {$[13.43]$} & {$[-0.17]$} & {$[-0.39]$} & {$[0.31]$} & [2.28] \\
\hline \multirow[t]{2}{*}{$S S I_{t-1}$} & $-.917^{* * *}$ & $1.171^{* * *}$ & $1.664^{* * *}$ & $2.773^{* * *}$ & $-2.24^{* * *}$ & $-.895^{* * * *}$ & -0.126 & 0.136 & 0.267 & 0.314 \\
\hline & {$[-6.81]$} & [2.89] & {$[2.79]$} & [3.91] & {$[-3.60]$} & {$[-8.24]$} & {$[-0.43]$} & {$[0.39]$} & {$[0.69]$} & [1.13] \\
\hline \multirow[t]{2}{*}{$S S I_{t}$} & $1.703^{* * *}$ & $2.946^{* * *}$ & $4.260^{* * *}$ & $5.161^{* * *}$ & $1.418^{* *}$ & $1.268^{* * * *}$ & $2.790^{* * * *}$ & $3.336^{* * *}$ & $4.058^{* * *}$ & $3.064^{* * *}$ \\
\hline & [13.64] & {$[7.54]$} & [7.35] & {$[7.46]$} & [2.39] & {$[12.36]$} & {$[9.62]$} & {$[9.62]$} & [10.39] & [11.01] \\
\hline \multirow[t]{2}{*}{$S S I_{t+1}$} & $0.439^{* * *}$ & $0.759^{*}$ & $1.408^{* *}$ & $2.004^{* * *}$ & $1.163^{*}$ & $0.525^{* * *}$ & $1.628^{* * *}$ & $2.190^{* * *}$ & $2.587^{* * *}$ & $2.834^{* \vec{*} *}$ \\
\hline & {$[3.40]$} & {$[1.85]$} & {$[2.36]$} & {$[2.81]$} & {$[1.84]$} & {$[5.59]$} & {$[6.11]$} & {$[6.86]$} & {$[7.12]$} & [10.98] \\
\hline \multirow[t]{2}{*}{$S S I_{t+2}$} & $-1.93^{* * *}$ & $-3.40^{* * * *}$ & $-4.92^{* * *}$ & $-5.54^{* * *}$ & $-6.93^{* * *}$ & $-1.39^{* * *}$ & $-2.37^{* * *}$ & $-2.63^{* * *}$ & $-3.03^{* * *}$ & $-3.77^{* * * *}$ \\
\hline & {$[-14.1]$} & {$[-8.05]$} & {$[-8.07]$} & {$[-7.67]$} & {$[-11.0]$} & {$[-15.5]$} & {$[-9.33]$} & {$[-8.50]$} & {$[-8.72]$} & {$[-15.3]$} \\
\hline $\operatorname{Adj}-R^{2}$ & 0.086 & 0.059 & 0.055 & 0.055 & 0.106 & 0.097 & 0.053 & 0.043 & 0.045 & 0.059 \\
\hline
\end{tabular}




\section{Table 16 (contd.): Put Options Market Regression with Lag and Lead Inventory Surprises}

This table reports the results of the regression model: $R_{t}=\alpha+\sum_{i=1}^{3} \beta_{i} R_{t-i}+\sum_{j=-2}^{2} \gamma_{j} S S I_{t-j}+\sum_{k=1}^{32} \theta_{k} S S M_{k t}+\varepsilon_{t}$, for the put option contracts. In the regressions, $R_{t}$ refers to the daily return of crude oil futures, $R_{t-i}$ is the $\mathrm{i}^{\text {th }}$ lagged daily return of crude oil futures, $S S I_{t-j}$ is the lag/lead standardized surprise that allows us to investigate news anticipation effects, and $S S M_{k t}$ refers to the standardized surprise of the $k^{t h}$ news variable on day $t$. Due to space limitations, we do not report the parameters for $S S M_{k t}$.

\begin{tabular}{|c|c|c|c|c|c|c|c|c|c|c|}
\hline & \multicolumn{10}{|c|}{ Expiration } \\
\hline & \multicolumn{5}{|c|}{3} & \multicolumn{5}{|c|}{4} \\
\hline & DITM & ITM & NTM & OTM & DOTM & DITM & ITM & NTM & OTM & DOTM \\
\hline \multirow[t]{2}{*}{$\alpha$} & $0.726^{\text {*** }}$ & $0.867^{* * * 4}$ & $-.410^{* * * *}$ & $-1.65^{* * *}$ & $-3.11^{* * *}$ & $0.265^{* * *}$ & $0.458^{* * * 4}$ & $-.135^{* * *}$ & $-.795^{* * *}$ & $-1.03^{* * *}$ \\
\hline & [31.43] & [16.34] & {$[-7.97]$} & {$[-29.7]$} & {$[-83.2]$} & [22.33] & {$[15.68]$} & {$[-5.23]$} & {$[-31.3]$} & {$[-64.7]$} \\
\hline \multirow[t]{2}{*}{$R_{t-1}$} & $-.023^{* * *}$ & $-.015^{* * *}$ & $-.036^{* * * *}$ & $-.019^{* * *}$ & $-.020^{* *_{*}^{* *}}$ & $-.018^{* * * *}$ & $-.021^{* * * *}$ & $-.073^{* * * *}$ & $-.066^{* * *}$ & $-.033^{* * *}$ \\
\hline & {$[-7.98]$} & {$[-3.40]$} & {$[-8.61]$} & {$[-4.86]$} & {$[-9.56]$} & {$[-7.61]$} & {$[-5.22]$} & {$[-20.6]$} & {$[-19.5]$} & {$[-19.8]$} \\
\hline \multirow[t]{2}{*}{$R_{t-2}$} & $-.013^{* * *}$ & $-.011^{* *}$ & $-.012^{* * *}$ & $0.007^{*}$ & $-.007^{* * *}$ & -0.004 & $-.007^{*}$ & $-.013^{* * *}$ & $0.008^{* *}$ & $0.023^{* * *}$ \\
\hline & {$[-4.40]$} & {$[-2.41]$} & {$[-2.87]$} & {$[1.82]$} & {$[-3.30]$} & {$[-1.55]$} & {$[-1.85]$} & {$[-3.65]$} & [2.43] & [13.94] \\
\hline \multirow{2}{*}{$R_{t-3}$} & $0.055^{\text {*** }}$ & 0.005 & $-.033^{* * * *}$ & $-.029^{* * *}$ & $-.052^{* * *}$ & $0.041^{* * *}$ & 0.003 & $-.025^{* * * *}$ & $-.015^{* * *}$ & $-.017^{* * *}$ \\
\hline & [19.25] & [1.18] & {$[-7.92]$} & {$[-7.34]$} & {$[-24.7]$} & [17.93] & {$[0.64]$} & {$[-6.97]$} & {$[-4.49]$} & {$[-10.1]$} \\
\hline \multirow[t]{2}{*}{$S S I_{t-2}$} & $1.184^{* * * *}$ & $0.252^{* *}$ & $-.216^{*}$ & -0.098 & 0.072 & $0.224^{* * *}$ & $0.112^{*}$ & $-.220^{* * * *}$ & $-.213^{* * * *}$ & $-.190^{* * * *}$ \\
\hline & {$[23.87]$} & [2.19] & {$[-1.91]$} & {$[-0.82]$} & {$[0.93]$} & {$[8.66]$} & {$[1.80]$} & {$[-3.94]$} & {$[-3.85]$} & {$[-5.41]$} \\
\hline \multirow[t]{2}{*}{$S S I_{t-1}$} & $-.644^{* * * *}$ & 0.164 & $0.410^{* * * *}$ & $0.372^{* * *}$ & $0.448^{* * *}$ & $-.572^{* * *}$ & $-.406^{* * *}$ & -0.044 & -0.05 & $0.165^{* * *}$ \\
\hline & {$[-12.7]$} & [1.44] & {$[3.74]$} & [3.14] & [5.84] & {$[-21.4]$} & {$[-6.49]$} & {$[-0.79]$} & {$[-0.91]$} & {$[4.81]$} \\
\hline \multirow[t]{2}{*}{$S S I_{t}$} & $0.885^{* * *}$ & $1.271^{* * *}$ & $1.452^{* * *}$ & $1.847^{* * *}$ & $1.569^{* * *}$ & $0.445^{* * *}$ & $0.498^{* * * *}$ & $0.655^{* * * *}$ & $0.748^{* * *}$ & $0.846^{* * *}$ \\
\hline & [17.85] & [11.33] & {$[13.02]$} & [15.39] & {$[20.21]$} & {$[17.42]$} & {$[8.28]$} & {$[11.86]$} & [13.62] & {$[24.85]$} \\
\hline \multirow[t]{2}{*}{$S S I_{t+1}$} & $0.562^{* * *}$ & $0.887^{* \text { *ै* }}$ & $1.039^{* * *}$ & $1.196^{* \vec{*} *}$ & $1.473^{* * * *}$ & $0.270^{* * *}$ & $0.585^{* * *}$ & $0.685^{* * *}$ & $0.775^{\text {**** }}$ & $0.987^{* \vec{*} *}$ \\
\hline & {$[12.10]$} & {$[7.98]$} & {$[9.54]$} & [10.17] & [19.35] & [10.84] & {$[9.66]$} & {$[12.47]$} & [14.35] & [29.16] \\
\hline \multirow[t]{2}{*}{$S S I_{t+2}$} & $-1.36^{* * *}$ & $-1.60^{* * *}$ & $-1.52^{* * *}$ & $-1.64^{* * *}$ & $-2.53^{* * *}$ & $-.564^{* * *}$ & $-.967^{* * *}$ & $-.815^{* * *}$ & $-.802^{* * *}$ & $-.900^{* * *}$ \\
\hline & {$[-29.0]$} & {$[-14.4]$} & {$[-14.0]$} & {$[-14.1]$} & {$[-33.9]$} & {$[-22.6]$} & {$[-16.1]$} & {$[-14.9]$} & {$[-15.1]$} & {$[-27.0]$} \\
\hline $\operatorname{Adj}-R^{2}$ & 0.096 & 0.053 & 0.04 & 0.041 & 0.046 & 0.091 & 0.06 & 0.046 & 0.041 & 0.037 \\
\hline
\end{tabular}




\section{Table 17: Call Option Regressions}

This table presents the results of the regression model: $R_{t}=\alpha+\sum_{i=1}^{3} \beta_{i} R_{t-i}+\gamma_{0} S S I_{t}+\theta R_{t}^{F}+\varepsilon_{t}$. The regressions are run on call options grouped by expiration and moneyness. Here, $R_{t}$ refers to the daily return of a call option, $R_{t-i}$ is the $\mathrm{i}^{\text {th }}$ lagged daily return of the same call option, $R_{t}^{F}$ refers to the return of the corresponding underlying futures contract, and $S S I_{t}=\left(A_{t}-E_{t}\right) / \sigma$ refers to the standardized surprise of crude oil inventory on day $\mathrm{t}$ (zero if there is no inventory news on day $\mathrm{t}$ ).

\begin{tabular}{|c|c|c|c|c|c|c|c|c|c|c|}
\hline & \multicolumn{10}{|c|}{ Expiration } \\
\hline & \multicolumn{5}{|c|}{1} & \multicolumn{5}{|c|}{2} \\
\hline & DITM & ITM & NTM & OTM & DOTM & DITM & ITM & NTM & OTM & DOTM \\
\hline \multirow[t]{2}{*}{$\alpha$} & $0.254^{* * * *}$ & 0.06 & $-2.62^{* * * *}$ & $-10.2^{* * *}$ & $-14.7^{* * *}$ & $0.107^{* * *}$ & $-.267^{* * *}$ & $-1.04^{* * *}$ & $-2.48^{* * * *}$ & $-5.93^{* * *}$ \\
\hline & [11.79] & [1.02] & {$[-22.0]$} & {$[-59.9]$} & {$[-70.0]$} & {$[6.30]$} & {$[-7.54]$} & {$[-18.5]$} & {$[-33.3]$} & {$[-76.1]$} \\
\hline \multirow[t]{2}{*}{$R_{t-1}$} & -0.002 & 0.002 & -0.001 & 0.006 & $-.040^{* * *}$ & -0.002 & $0.009^{* * * *}$ & $0.014^{* * * *}$ & $0.018^{* * * *}$ & -0.001 \\
\hline & {$[-1.16]$} & {$[0.91]$} & {$[-0.27]$} & [1.54] & {$[-8.29]$} & {$[-1.30]$} & {$[4.48]$} & [5.38] & [6.09] & {$[-0.20]$} \\
\hline \multirow[t]{2}{*}{$R_{t-2}$} & $-.007^{* * *}$ & $-.006^{* * *}$ & $-.007^{* \frac{3}{*}}$ & -0.003 & $0.010^{*}$ & $-.007^{* * * *}$ & $-.004^{* * *}$ & -0.001 & 0.003 & $0.013^{* * *}$ \\
\hline & {$[-4.01]$} & {$[-2.23]$} & {$[-1.98]$} & {$[-0.79]$} & [1.95] & {$[-4.31]$} & {$[-2.05]$} & {$[-0.21]$} & {$[1.10]$} & {$[4.70]$} \\
\hline \multirow[t]{2}{*}{$R_{t-3}$} & -0.003 & $-.011^{* * * *}$ & $-.020^{* * * *}$ & $-.029^{* *_{*}^{* *}}$ & $-.050^{* * *}$ & $-.004^{* * * *}$ & $-.008^{* * *}$ & $-.009^{* * *}$ & $-.013^{* * *}$ & $-.020^{* * *}$ \\
\hline & {$[-1.60]$} & {$[-4.35]$} & {$[-5.82]$} & {$[-6.54]$} & {$[-9.51]$} & {$[-2.84]$} & {$[-3.71]$} & {$[-3.39]$} & {$[-4.38]$} & {$[-7.32]$} \\
\hline \multirow[t]{2}{*}{$S S I_{t}$} & 0.04 & $-.430^{* * * *}$ & $-.792^{* * * *}$ & $-1.06^{* * *}$ & $-3.30^{* * *}$ & $-.263^{* * *}$ & $-.454^{* * * *}$ & $-.730^{* * * *}$ & $-1.06^{* * *}$ & $-2.09^{* * * *}$ \\
\hline & {$[0.93]$} & {$[-3.60]$} & {$[-3.25]$} & {$[-3.08]$} & {$[-8.74]$} & {$[-7.06]$} & {$[-5.80]$} & {$[-5.84]$} & {$[-6.29]$} & {$[-12.6]$} \\
\hline \multirow{2}{*}{$R_{t}^{F}$} & $4.572^{* * *}$ & $9.851^{* * * *}$ & $13.94^{* * * *}$ & $15.75^{* * *}$ & $10.05^{* * *}$ & $3.951^{* * * *}$ & $7.404^{* * * *}$ & $9.121^{* * * *}$ & $10.58^{* * *}$ & $7.544^{* * * *}$ \\
\hline & {$[503.0]$} & [378.1] & [263.9] & [216.1] & [166.3] & [569.3] & [453.6] & [351.5] & [308.6] & [286.8] \\
\hline \multirow[t]{4}{*}{$\operatorname{Adj}-R^{2}$} & 0.861 & 0.904 & 0.838 & 0.762 & 0.643 & 0.868 & 0.915 & 0.877 & 0.827 & 0.618 \\
\hline & \multicolumn{10}{|c|}{ Expiration } \\
\hline & \multicolumn{5}{|c|}{3} & \multicolumn{5}{|c|}{4} \\
\hline & DITM & ITM & NTM & OTM & DOTM & DITM & ITM & NTM & OTM & DOTM \\
\hline \multirow[t]{2}{*}{$\alpha$} & $0.065^{* * *}$ & $-.184^{* * * *}$ & $-.420^{* * *}$ & $-.694^{* * * *}$ & $-2.22^{* * * *}$ & $0.038^{* * * *}$ & $-.019^{* *}$ & $-.109^{* * * *}$ & $-.182^{* * * *}$ & $-.626^{* * * *}$ \\
\hline & {$[9.38]$} & {$[-14.4]$} & {$[-22.9]$} & {$[-28.1]$} & {$[-82.5]$} & {$[9.80]$} & {$[-2.48]$} & {$[-10.2]$} & {$[-13.6]$} & {$[-41.3]$} \\
\hline \multirow[t]{2}{*}{$R_{t-1}$} & $-.002^{* * *}$ & $0.005^{* * * *}$ & $0.008^{* * * *}$ & $0.013^{* * *}$ & $0.015^{* * * *}$ & $-.003^{* * *}$ & 0.001 & $-.006^{* * *}$ & $-.009^{* * * *}$ & $-.007^{* \text { 雨 }}$ \\
\hline & {$[-2.93]$} & [4.97] & {$[5.85]$} & [8.29] & {$[10.64]$} & {$[-4.73]$} & {$[0.56]$} & {$[-4.72]$} & {$[-5.82]$} & {$[-5.39]$} \\
\hline \multirow[t]{2}{*}{$R_{t-2}$} & $0.004^{* * * *}$ & 0.001 & $0.008^{* * *}$ & $0.011^{* * *}$ & $0.036^{* * * *}$ & $0.008^{* * *}$ & $0.005^{* * *}$ & $0.007^{* * * *}$ & $0.017^{* * * *}$ & $0.050^{* * * *}$ \\
\hline & [5.11] & {$[0.69]$} & [6.14] & [6.64] & {$[24.68]$} & {$[11.71]$} & {$[5.12]$} & {$[5.04]$} & [11.39] & {$[40.05]$} \\
\hline \multirow[t]{2}{*}{$R_{t-3}$} & 0.000 & $-.003^{* * *}$ & 0.001 & -0.002 & $-.010^{* * * *}$ & $0.004^{* * * *}$ & 0.000 & $0.004^{* * *}$ & $0.006^{* * * *}$ & 0.001 \\
\hline & {$[-0.02]$} & {$[-2.86]$} & {$[0.41]$} & {$[-0.94]$} & {$[-6.88]$} & {$[5.70]$} & {$[0.30]$} & [3.19] & {$[4.06]$} & {$[0.97]$} \\
\hline \multirow[t]{2}{*}{$S S I_{t}$} & $-.107^{* \text { *** }}$ & $-.244^{* * *}$ & $-.390^{* * *}$ & $-.588^{* * *}$ & $-1.23^{* * *}$ & $-.065^{* * *}$ & $-.169^{* * *}$ & $-.239^{* * *}$ & $-.303^{* * *}$ & $-.172^{* * *}$ \\
\hline & {$[-7.28]$} & {$[-8.79]$} & {$[-9.76]$} & {$[-10.8]$} & {$[-21.4]$} & {$[-7.98]$} & {$[-9.92]$} & {$[-10.3]$} & {$[-10.5]$} & {$[-5.35]$} \\
\hline \multirow[t]{2}{*}{$R_{t}^{F}$} & $3.759^{* * * *}$ & $5.758^{* * * *}$ & $6.442^{* * *}$ & $6.968^{* * *}$ & $5.125^{* * * *}$ & $3.095^{* * * *}$ & $4.263^{* * *}$ & $4.501^{* * * *}$ & $4.526^{* * * *}$ & $3.682^{* * * *}$ \\
\hline & [1123] & [886.5] & [688.3] & [580.8] & [529.3] & [1461] & [950.3] & [722.6] & [627.6] & [566.9] \\
\hline $\operatorname{Adj}-R^{2}$ & 0.896 & 0.922 & 0.885 & 0.846 & 0.572 & 0.915 & 0.913 & 0.865 & 0.844 & 0.509 \\
\hline
\end{tabular}




\section{Table 18: Put Option Regression}

This table presents the results of the regression model: $R_{t}=\alpha+\sum_{i=1}^{3} \beta_{i} R_{t-i}+\gamma_{0} S S I_{t}+\theta R_{t}^{F}+\varepsilon_{t}$. The regressions are run on put options grouped by expiration and moneyness. Here, $R_{t}$ refers to the daily return of a call option, $R_{t-i}$ is the $\mathrm{i}^{\text {th }}$ lagged daily return of the same call option, $R_{t}^{F}$ refers to the return of the corresponding underlying futures contract, and $S S I_{t}=\left(A_{t}-E_{t}\right) / \sigma$ refers to the standardized surprise of crude oil inventory on day $\mathrm{t}$.

\begin{tabular}{|c|c|c|c|c|c|c|c|c|c|c|}
\hline & \multicolumn{10}{|c|}{ Expiration } \\
\hline & \multicolumn{5}{|c|}{1} & \multicolumn{5}{|c|}{2} \\
\hline & DITM & ITM & NTM & OTM & DOTM & DITM & ITM & NTM & OTM & DOTM \\
\hline \multirow[t]{2}{*}{$\alpha$} & $0.587^{* * *}$ & $0.419^{* * *}$ & $-2.84^{* * *}$ & $-9.82^{* * *}$ & $-14.1^{* * *}$ & $0.450^{* * *}$ & 0.075 & $-.926^{* * *}$ & $-2.27^{* * *}$ & $-5.76^{* * *}$ \\
\hline & [15.69] & [5.33] & {$[-22.2]$} & {$[-57.3]$} & {$[-72.4]$} & {$[16.25]$} & [1.57] & {$[-15.5]$} & {$[-31.0]$} & {$[-78.9]$} \\
\hline \multirow[t]{2}{*}{$R_{t-1}$} & $0.022^{* * *}$ & $0.033^{* * *}$ & $0.023^{* * *}$ & $0.020^{* * * *}$ & $-.016^{* * *}$ & $0.016^{* * *}$ & $0.023^{* * *}$ & $0.023^{* * *}$ & $0.024^{* * *}$ & $-.014^{* \text { **** }}$ \\
\hline & {$[7.49]_{* * *}$} & {$[11.44]$} & {$[6.32]^{*}$} & [4.82] & {$[-3.47]$} & {$[5.62]_{* * *}$} & {$[8.41]$} & [7.81] & [7.85] & {$[-5.61]$} \\
\hline \multirow[t]{2}{*}{$R_{t-2}$} & $0.024^{* * *}$ & $0.022^{* *_{*}^{* *}}$ & $-.007^{* *}$ & -0.003 & $-.040^{* * *}$ & $0.011^{* * *}$ & $0.005^{*}$ & 0.004 & 0.004 & $-.010^{* * * * *}$ \\
\hline & {$[7.94]$} & [7.07] & {$[-1.96]$} & {$[-0.76]$} & {$[-8.28]$} & {$[3.89]$} & {$[1.84]$} & {$[1.30]$} & {$[1.45]$} & {$[-3.66]$} \\
\hline \multirow[t]{2}{*}{$R_{t-3}$} & $0.015^{* * *}$ & $-.007^{* * *}$ & $-.018^{* * *}$ & $-.022^{* * * *}$ & $-.038^{* \overrightarrow{* * *}}$ & $0.018^{* * *}$ & $-.012^{* * *}$ & $-.015^{* * *}$ & $-.019^{* * *}$ & $-.048^{* \text { *ै* }}$ \\
\hline & {$[5.11]_{* * *}$} & [-2.49] & {$[-4.91]$} & {$[-5.02]$} & {$[-7.74]_{* * *}$} & {$[6.71]_{* * *}$} & {$[-4.34]$} & {$[-5.24]$} & [-6.39] & {$[-19.0]_{* * *}$} \\
\hline \multirow[t]{2}{*}{$S S I_{t}$} & $0.592^{* * *}$ & 0.027 & 0.144 & 0.091 & $-.929^{* * *}$ & $0.564^{* * *}$ & 0.072 & 0.015 & -0.159 & $-.495^{* * * *}$ \\
\hline & {$[8.26]_{* * *}$} & {$[0.18]_{* *}$} & {$[0.56]_{* * *}$} & {$[0.28]$} & {$[-2.77]$} & {$[9.27]_{* * *}$} & {$[0.69]$} & {$[0.11]$} & {$[-0.98]$} & {$[-3.31]$} \\
\hline \multirow[t]{2}{*}{$R_{t}^{F}$} & $-2.73^{* * *}$ & $-9.17^{* * *}$ & $-13.2^{* * *}$ & $-15.1^{* * *}$ & $-11.2^{* * * *}$ & $-2.03^{* * *}$ & $-6.69^{* * *}$ & $-8.62^{* * *}$ & $-9.96^{* * * *}$ & $-9.84^{* \text { **** }}$ \\
\hline & {$[-260]$} & {$[-290]$} & {$[-242]$} & {$[-214]$} & {$[-175]$} & {$[-274]$} & {$[-334]$} & {$[-319]$} & {$[-302]$} & {$[-333]$} \\
\hline \multirow[t]{4}{*}{$\operatorname{Adj}-R^{2}$} & 0.676 & 0.860 & 0.814 & 0.777 & 0.701 & 0.648 & 0.875 & 0.858 & 0.836 & 0.726 \\
\hline & \multicolumn{10}{|c|}{ Expiration } \\
\hline & \multicolumn{5}{|c|}{3} & \multicolumn{5}{|c|}{4} \\
\hline & DITM & ITM & NTM & OTM & DOTM & DITM & ITM & NTM & OTM & DOTM \\
\hline \multirow[t]{2}{*}{$\alpha$} & $0.307^{* * * *}$ & $0.052^{* * * *}$ & $-.343^{* * *}$ & $-.634^{* * *}$ & $-1.68^{* * * *}$ & $0.104^{* * *}$ & $0.077^{* * *}$ & $-.089^{* * * *}$ & $-.185^{* * *}$ & $-.333^{* * *}$ \\
\hline & [24.33] & {$[2.78]_{* * *}$} & {$[-18.0]$} & {$[-29.6]$} & {$[-83.5]$} & {$[19.78]$} & {$[7.19]_{* * *}$} & {$[-8.50]$} & {$[-17.8]$} & {$[-33.5]$} \\
\hline \multirow[t]{2}{*}{$R_{t-1}$} & $0.012^{\text {**** }}$ & $0.022^{* * *}$ & $0.019^{* * *}$ & $0.021^{* * *}$ & $0.016^{* * *}$ & $0.014^{* * *}$ & $0.015^{* * *}$ & $-.006^{* \vec{*} *}$ & $-.008^{* * * *}$ & $-.016^{* \text { *** }}$ \\
\hline & {$[7.59]$} & {$[14.14]$} & {$[12.34]$} & {$[13.73]$} & {$[14.28]$} & {$[14.00]$} & [10.23] & {$[-3.95]$} & {$[-5.57]$} & {$[-15.4]$} \\
\hline \multirow[t]{2}{*}{$R_{t-2}$} & $0.012^{* * *}$ & $0.009^{* 3 *}$ & $0.008^{* 3 *}$ & $0.008^{* k_{*}^{* *}}$ & $0.006^{* 3 *}$ & $0.005^{* * *}$ & $0.003^{* *}$ & 0.002 & $0.004^{* * *}$ & $0.014^{* * *}$ \\
\hline & [7.79] & {$[5.75]_{* * *}$} & {$[5.24]_{* * *}$} & {$[5.45]_{* * *}$} & {$[5.07]_{* * *}$} & {$[5.15]$} & {$[2.01]_{* * *}$} & {$[1.56]_{* * *}$} & {$[2.94]_{* * *}$} & {$[13.55]$} \\
\hline \multirow[t]{2}{*}{$R_{t-3}$} & 0.000 & $-.013^{* * *}$ & $-.012^{* * *}$ & $-.014^{* * * *}$ & $-.026^{* * *}$ & 0.002 & $-.009^{* * *}$ & $-.011^{* * *}$ & $-.010^{* * *}$ & $-.007^{* * * *}$ \\
\hline & {$[-0.15]$} & {$[-8.33]$} & {$[-7.38]$} & {$[-9.18]$} & {$[-22.9]$} & {$[1.49]_{* * *}$} & {$[-6.43]$} & {$[-7.57]$} & {$[-7.35]$} & {$[-7.12]$} \\
\hline \multirow[t]{2}{*}{$S S I_{t}$} & $0.326^{* * *}$ & -0.03 & -0.002 & $-.091^{*}$ & $-.325^{* \vec{*} *}$ & $0.112^{* * *}$ & $-.065^{* 3 *}$ & $-.061^{* \vec{*} *}$ & $-.114^{* \vec{*} *}$ & $-.163^{* * *}$ \\
\hline & {$[12.48]$} & {$[-0.75]$} & {$[-0.05]$} & {$[-1.93]$} & {$[-7.61]$} & [9.94] & {$[-2.98]$} & {$[-2.73]$} & {$[-5.06]$} & {$[-7.56]$} \\
\hline \multirow[t]{2}{*}{$R_{t}^{F}$} & $-1.92^{* * *}$ & $-4.77^{* * *}$ & $-5.77^{* * *}$ & $-6.39^{* *_{*} *}$ & $-6.95^{* * *}$ & $-1.73^{* * *}$ & $-3.24^{* * *}$ & $-3.73^{* 3 *}$ & $-3.87^{* * *}$ & $-4.14^{* * * *}$ \\
\hline & {$[-523]$} & [-591] & [-615] & [-604] & [-728] & [-867] & [-638] & [-639] & {$[-658]$} & [-753] \\
\hline $\operatorname{Adj}-R^{2}$ & 0.715 & 0.880 & 0.866 & 0.852 & 0.709 & 0.810 & 0.873 & 0.839 & 0.834 & 0.612 \\
\hline
\end{tabular}




\section{Figure 1: Futures Returns and Volume around EIA Oil Announcements}

The figure shows average volume and cumulative average returns for oil futures around the EIA crude oil announcement day, which is resented as time 0. Each graph reports averages for contracts with different expirations. The circle $\left(^{\circ}\right)$ line represents the average over all announcements. The cross line $\left.{ }^{(} \mathrm{x}\right)$ represents the average over all positive inventory surprises and the triangle $(\Delta)$ line represents the average return over all negative inventory surprises.

CL1

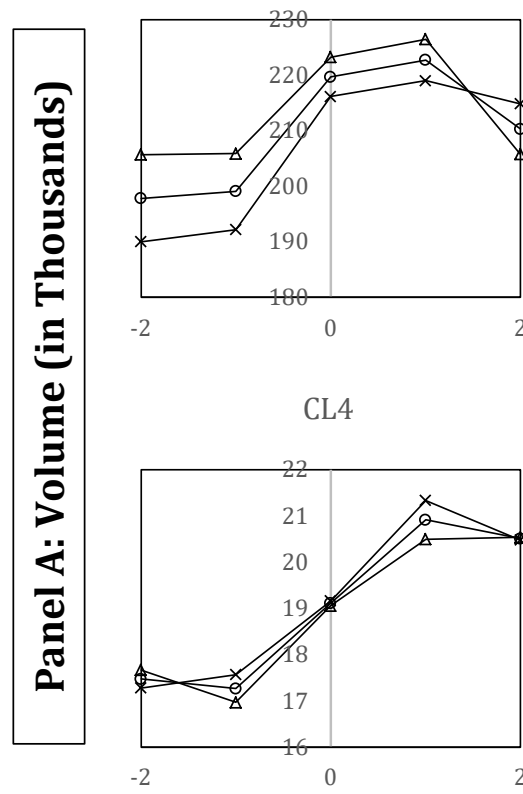

CL1

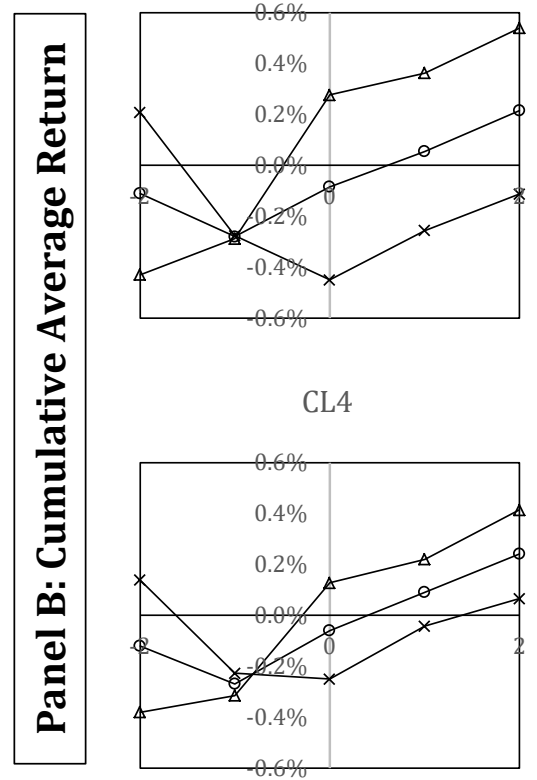

CL2

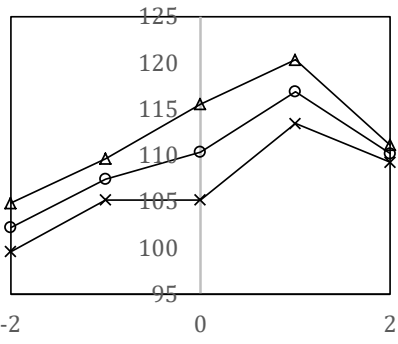

CL5

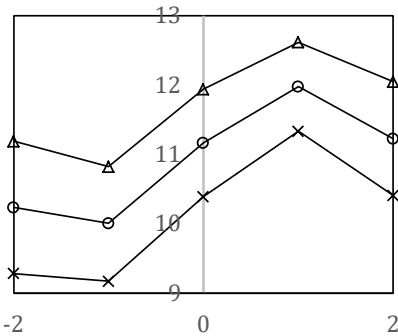

CL2

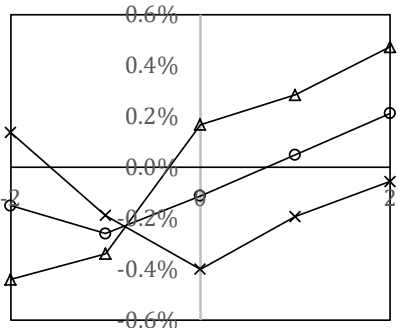

CL5

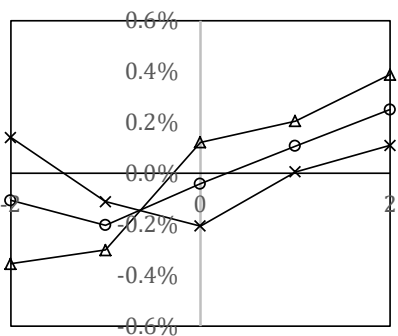

CL3

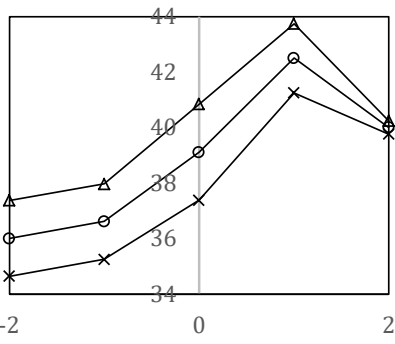

CL6

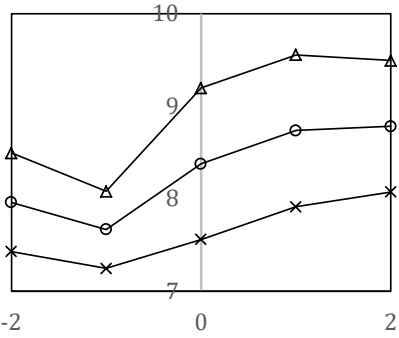

CL3

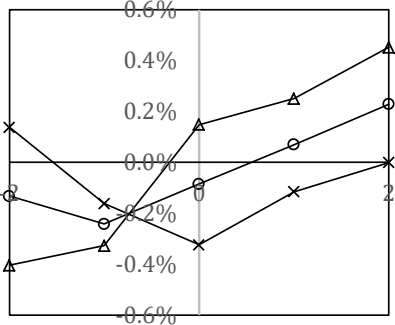

CL6

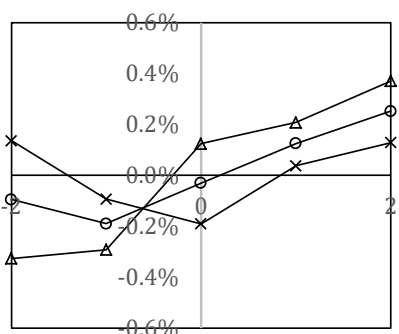




\section{Figure 2: Cumulative Call Option Returns around EIA Oil Announcements}

The figure shows cumulative average returns for call options with different expirations and moneyness. The circle $\left(^{\circ}\right)$ line represents the average over all announcements. The cross line $\left({ }^{\mathrm{x}}\right)$ represents the average over all positive inventory surprises and the triangle $(\Delta)$ line represents the average return over all negative inventory surprises.
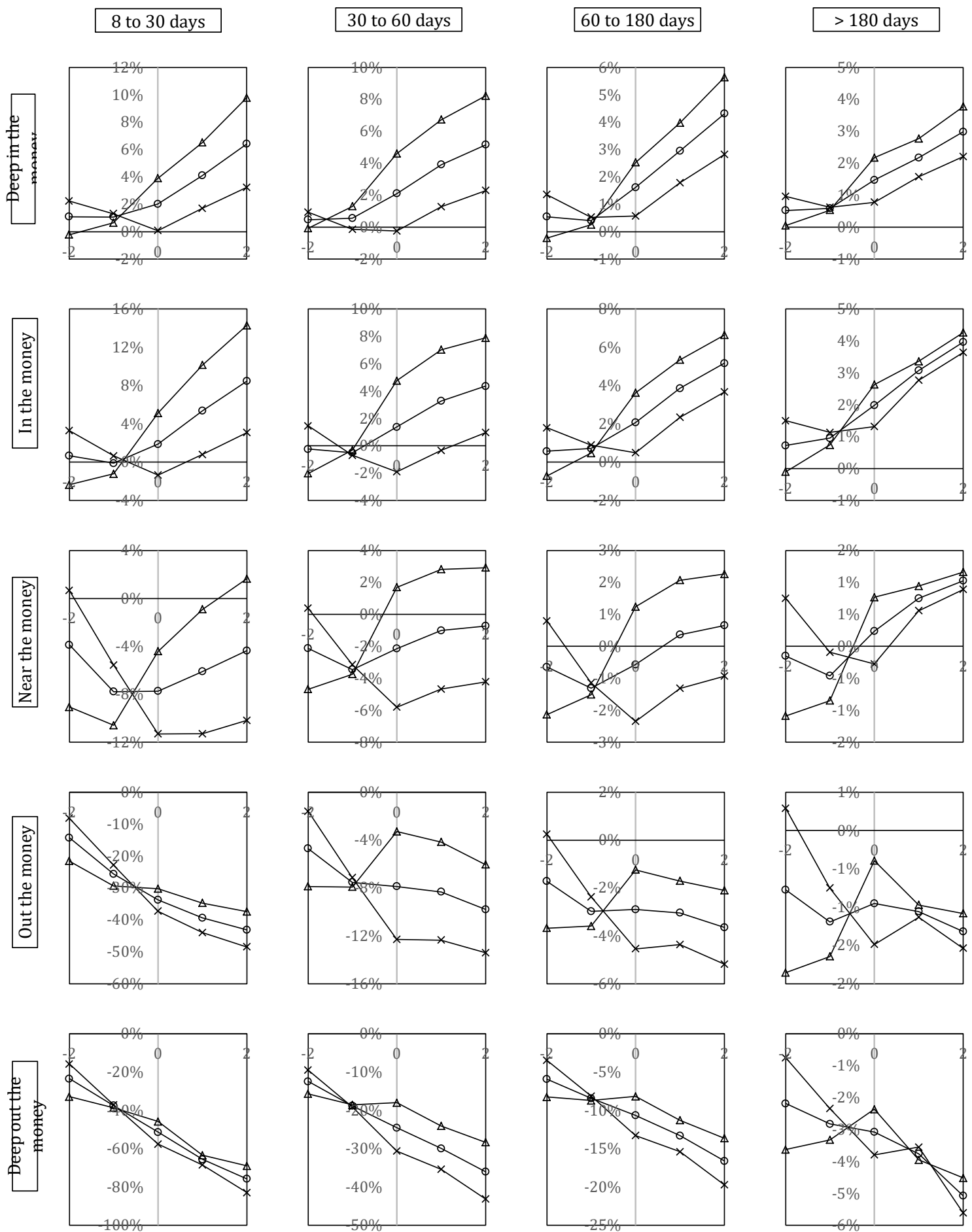


\section{Figure 3: Cumulative Put Option Returns around EIA Oil Announcements}

The figure shows cumulative average returns for put options with different expirations and moneyness. The circle $\left(^{\circ}\right)$ line represents the average over all announcements. The cross line $\left({ }^{\mathrm{x}}\right)$ represents the average over all positive inventory surprises and the triangle $(\Delta)$ line represents the average return over all negative inventory surprises.
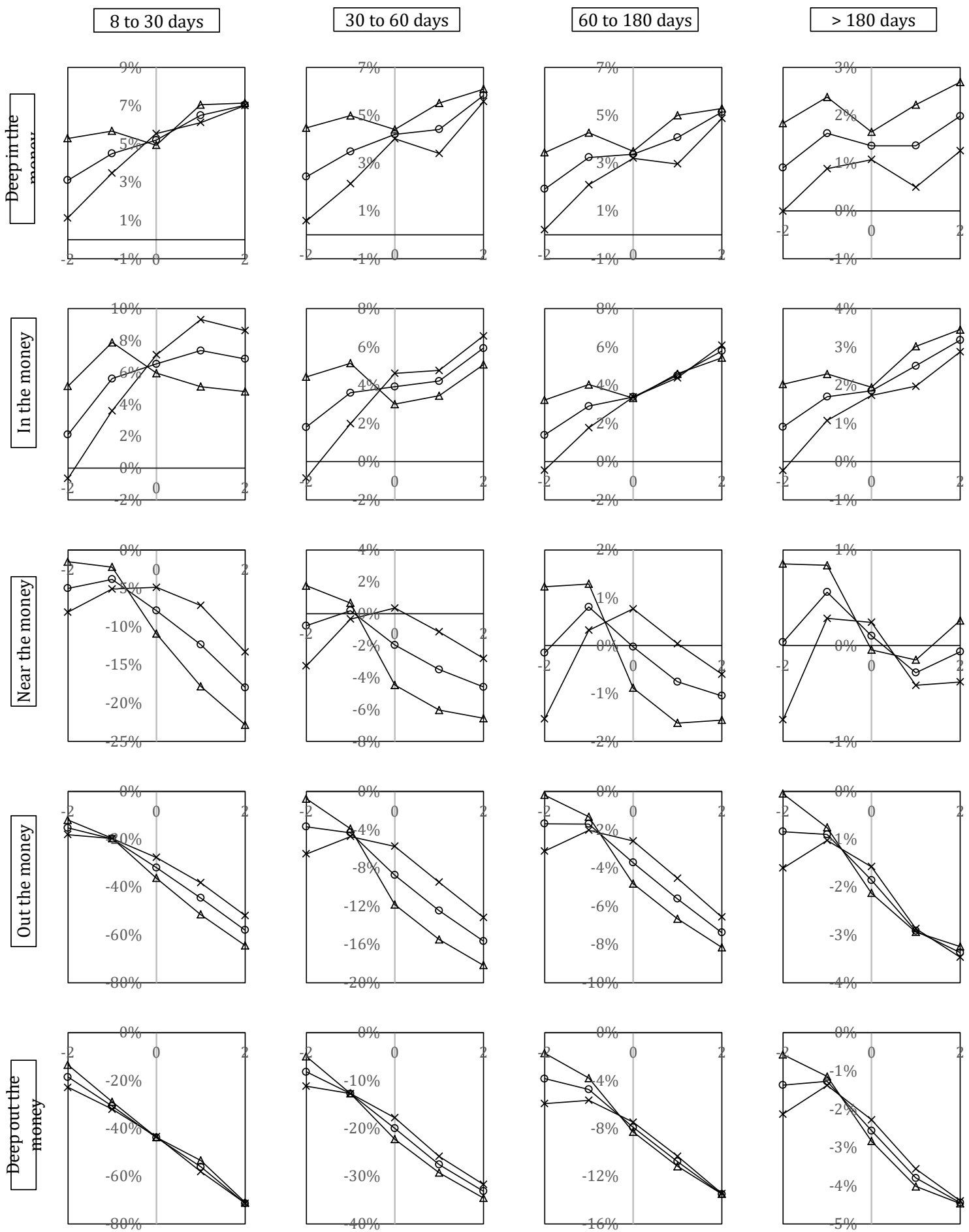